\title{
Managing classroom behavior of Head Start children using response cost and token economy procedures
}

Jennifer D. Tiano

West Virginia University

Follow this and additional works at: https://researchrepository.wvu.edu/etd

\section{Recommended Citation}

Tiano, Jennifer D., "Managing classroom behavior of Head Start children using response cost and token economy procedures" (2004). Graduate Theses, Dissertations, and Problem Reports. 814.

https://researchrepository.wvu.edu/etd/814

This Thesis is protected by copyright and/or related rights. It has been brought to you by the The Research Repository @ WVU with permission from the rights-holder(s). You are free to use this Thesis in any way that is permitted by the copyright and related rights legislation that applies to your use. For other uses you must obtain permission from the rights-holder(s) directly, unless additional rights are indicated by a Creative Commons license in the record and/ or on the work itself. This Thesis has been accepted for inclusion in WVU Graduate Theses, Dissertations, and Problem Reports collection by an authorized administrator of The Research Repository @ WVU. For more information, please contact researchrepository@mail.wvu.edu. 
Managing Classroom Behavior of Head Start Children Using Response Cost and Token Economy Procedures

Jennifer D. Tiano

Thesis submitted to the Eberly College of Arts and Sciences

at West Virginia University

in partial fulfillment of the requirements

for the degree of

Master of Arts

in

Psychology

Cheryl B. McNeil, Ph.D., Chair

Cynthia M. Anderson, Ph.D.

Lindsey L. Cohen, Ph.D.

Department of Psychology

Morgantown, West Virginia 2004

Keywords: Classroom Behavior, Head Start, Response Cost, School, Token Economy 


\begin{abstract}
Managing Classroom Behavior of Head Start Children Using Response Cost and Token Economy Procedures
\end{abstract}

Jennifer D. Tiano

The efficacy of three behavior management techniques used in a Head Start classroom was examined. The three techniques included: (a) techniques currently used by the teacher, (b) response cost, and (c) the Level System (token economy). The current study used an ABACA single subject withdrawal design with follow-up where all conditions were implemented until stability was reached. Classroom behavior was evaluated by both behavioral observation and teacher report. Children's behavior, teacher skill, number of time-outs, and satisfaction with behavior management techniques (i.e., teacher, parent, and child) were examined. No conclusions could be made concerning the efficacy (i.e., inappropriate behavior, class manageability, number of time-outs) of the techniques. The teacher reported more satisfaction with current strategies, parents with the Level System, and students with the response cost program. Finally, teachers used more labeled praise statements and fewer critical statements during the Level System condition than all other conditions. 
Table of Contents

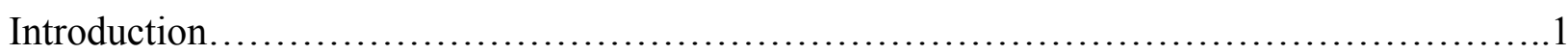

Difficulties Associated With Disruptive Behaviors.................................

Classroom Management Techniques..........................................5

Time-out............................................................

Response Cost....................................................6

Token Economies........................................................9

The Level System.................................................. 13

Comparing Response Cost and Token Economy Procedures.........................17

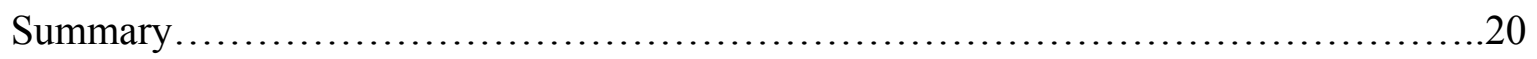

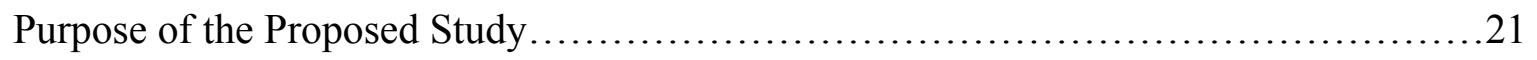

Hypotheses......................................................23

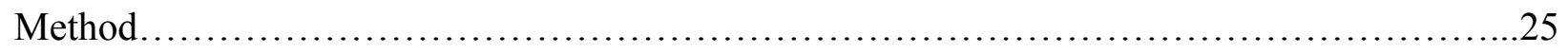

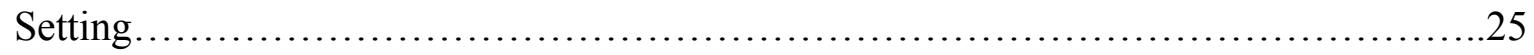

Participant Selection......................................................25

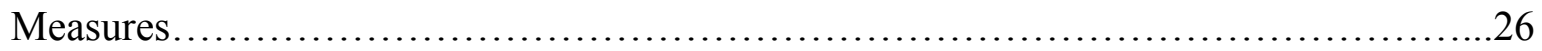

Participant Selection Measure............................................26

Treatment Efficacy Measures...........................................26

Satisfaction Measures.......................................................29

Treatment Integrity Measure........................................... 31

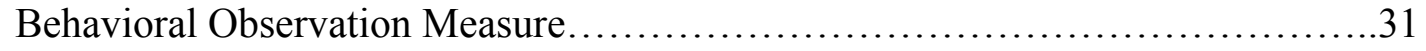

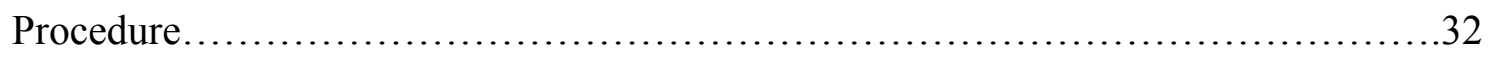

Teacher Training...................................................... 32 
Classroom Observations....................................................33

Experimental Conditions............................................... 34

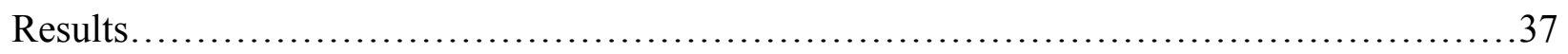

Efficacy........................................................... 37

Satisfaction......................................................... 39

Teacher Skill......................................................41

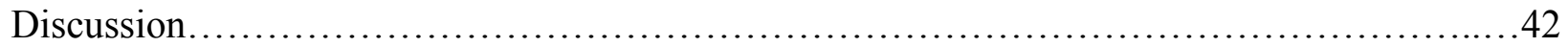

Limitations.......................................................48

Participant Selection............................................48

Observation Assessment............................................48

Study Confounds.............................................49

Directions for Future Research.......................................... 51

References..................................................................53

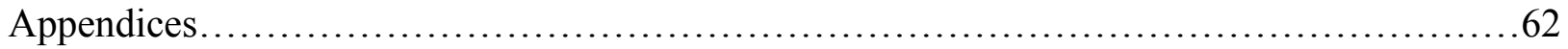

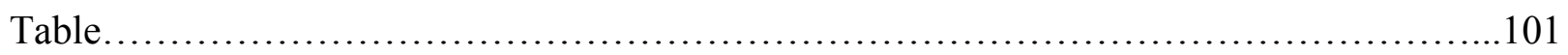

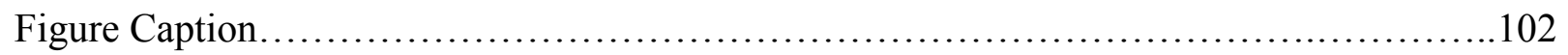

Figures................................................................. 103 
Managing Classroom Behavior of Head Start Children Using Response Cost and Token

\section{Economy Procedures}

Problematic behaviors exhibited by young children have become a topic of concern.

Research has found that the most common mental health problem in preschool-age children is externalizing behavior (Campbell, 1990). These behavior problems extend into the classroom as well, and behaviors that disrupt the classroom environment have been increasing in recent years (as cited in Lara, McCabe, \& Brooks-Gunn, 2000). More specifically, Head Start staff are reporting an increase in the number of children displaying challenging and disruptive behaviors (Piotrkowski, Collins, Knitzer, \& Robinson, 1994). Forty-eight percent of teachers of young children indicated having students with severe disruptive behaviors in the classroom and $41 \%$ of teachers reported a decrease in time devoted to learning due to attending to these behavioral problems (Peter D. Hart Research Associates, 1995). Approximately 10-15\% of children in preschool exhibit problem behaviors that could be classified in the moderate to severe range (Campbell, 1995). Keenan and Wakschlag (2000) found that almost half of their sample of 79 clinic-referred preschool children (ages 2.5 to 5.5) met the Diagnostic and Statistical ManualFourth Edition (DSM-IV) criteria for conduct disorder while three quarters met criteria for oppositional defiant disorder. In addition, approximately $8-12 \%$ of children have problems that would benefit from intervention (Brandenberg, Friedman, \& Silver, 1987).

Despite the increase in classroom behavior problems, teachers reported deficiencies in managing these behaviors. Merrett and Wheldall (1993) found that $72 \%$ of teachers were displeased with the training they received in classroom behavior management while almost $75 \%$ of teachers reported they were not prepared to manage children with special needs, including behavior problems. In fact, $37 \%$ of Head Start staff identified classroom behavior problems as a 
major concern for Head Start children (Piotrkowski, Collins, Knitzer, \& Robinson, 1994).

Surprisingly, Head Start research has found that Head Start children with behavior problems show little or no improvement in either disruptive behavior or emotional problems from the beginning to the end of the program year (U.S. Dept. of Health \& Human Resources, 2001). Behavior management strategies comprised 3 of the top 5 areas in which Head Start staff requested additional training (Buscemi, Bennett, Thomas, \& DeLuca, 1995). Teachers indicated that additional training may reduce stress and help decrease problem behaviors among students (Merrett \& Wheldall, 1993). Therefore, it is important to provide classroom instructors with effective strategies to manage classroom behaviors.

The current study examined the efficacy of three behavior management strategies used in Head Start classrooms: (a) techniques currently being used by the teacher, (b) response cost, and (c) the Level System. The techniques used by the teacher and teacher's aide prior to treatment implementation served as the baseline and withdrawal conditions of the study. The response cost program consisted of a board with four levels. The first three levels have sunshines and comprised the "sunny zone" of the board. The bottom level had clouds and comprised the "cloudy zone" of the board. A shape is assigned to each child in the classroom. Shapes were moved down contingent upon child inappropriate behavior (e.g., poking neighbor). The teacher gave a verbal warning for inappropriate behavior. If the inappropriate behavior continued, that child's shape was moved down one level. However, a shape was moved down without a warning for destruction of property and hurting. At specified times throughout the day each child whose shape was in the sunny zone received a reward. The Level System (McNeil \& Filcheck, 2001) possesses characteristics of both a token economy and response cost and provides teachers of young children with strategies in the management of behavior problems. The Level System was 
designed as a whole-class approach to behavior management. The Level System has seven levels: three sunny levels, one neutral level, and three cloudy levels. Each child in the classroom used the same shape they were assigned in the response cost condition. For appropriate behavior, the teacher provided social reinforcement (i.e., labeled praise) and moved the children's shapes up one level. For inappropriate behavior, the teacher provided a warning and if the behavior continued, the shape was moved down one level. However, shapes were moved down one level without a warning for destruction of property or hurting others. At specified times throughout the day the children with shapes in the sunny level received a reward. The current study also examined teacher satisfaction with the above mentioned classroom behavior management techniques.

This paper is organized in the following manner. First, problems associated with exhibiting disruptive behavior during preschool years are discussed. Second, strategies currently used to manage behavior in the classroom (i.e., time-out, response cost, token economy) are reviewed. Third, the Level System, a token economy procedure with response cost, is discussed in detail. Fourth, the literature comparing response cost and token economy procedures are reviewed. Finally, the proposed study is overviewed and hypotheses and data analyses are discussed.

\section{Difficulties Associated With Disruptive Behaviors}

Preschool children that exhibit behavior problems may require early interventions as these problems have been shown to continue and worsen as these children get older. Behavior problems in preschool years have been associated with antisocial behaviors and internalizing problems in childhood and adolescence (Campbell, 1995; Fischer, Rolf, Hasazi, \& Cummings, 1984). In fact, research has indicated that externalizing behaviors in preschool can predict continuing difficulties for up to 7 years (Campbell \& Ewing, 1990; McGee, Silva, \& Williams, 
1984). Schonfeld, Shaffer, O'Connor, and Portnoy (1988) found that one of the three most important predictors of conduct disorder in adolescence was engaging in aggressive behaviors as a child. In addition, retrospective data indicated that approximately $70-90 \%$ of a sample of individuals who engaged in violent acts exhibited aggressive behaviors as a young child (Loeber, 1990).

Behavior problems in preschool not only are related to externalizing behaviors later in life, but also academic difficulties and failures. More specifically, academic failure is associated with early problem behaviors such as inattention and noncompliance (Molina, Pelham, Blumenthal, \& Galiszewski, 1998). Classroom misbehavior has been associated with poor performance on standardized tests as well as a decrease in the amount of time devoted to studying (Stage \& Quiroz, 1997). Children who engaged in childhood conduct disordered behaviors had reading difficulties (Sturge, 1982). In addition, children enrolled in Head Start who displayed behavior problems were more likely to have difficulty with language and social skills (Kaiser, Hancock, Cai, Foster, \& Hester, 2000). In fact, many studies have found that peer rejection is common for children exhibiting externalizing behaviors (DeRosier, Cillessen, Coie, \& Dodge, 1994; KraatzKeiley, Bates, Dodge, \& Pettit, 2000; Laird, Jordan, Dodge, Pettit, \& Bates, 2001; Rubin \& Mills, 1988; Stormshak, Bierman, Bruschi, Dodge, \& Coie, 1999; \& Taylor, 1989). This peer rejection has been has been related to low self-esteem and feelings of isolation (Boivin, Hymel, \& Burkowski, 1995; French, Conrad, \& Turner, 1995; \& Pettit, Clawson, Dodge, \& Bates, 1996).

Despite the many difficulties associated with externalizing behavior problems, many children with these difficulties remain unidentified. Many preschool children who were engaging in behaviors that could be classified as a behavior disorder neither were involved in special 
programs nor were receiving mental health consultation services (Beare \& Lynch, 1986). In addition, Forness, Serna, Kavale, and Nielsen (1998) suggested that Head Start children displaying externalizing behaviors are under-identified by as much as $50 \%$ of the actual rate.

In sum, research has shown that behavior problems exhibited in preschool years may lead to many difficulties later in life. More specifically, externalizing behaviors at a young age have been associated with future problems such as antisocial behaviors, internalizing problems (Campbell, 1995; Fischer, Rolf, Hasazi, \& Cummings, 1984), and academic difficulties (Kaiser, Hancock, Cai, Foster, \& Hester, 2000; Molina, Pelham, Blumenthal, \& Galiszewski, 1998; Stage \& Quiroz, 1997; \& Sturge, 1982). Finally, many children experiencing problems with managing their behavior are under-identified and not receiving the intervention services they need (Beare \& Lynch, 1986; \& Forness, Serna, Kavale, \& Nielsen, 1998).

\section{Classroom Behavior Management Techniques}

Many techniques have been employed in classrooms to assist teachers in managing behavior including time-out, response cost, and token economies. Research has found these strategies to be efficacious in reducing undesirable behavior in the classroom. Both advantages and disadvantage; however, should be considered when determining the type of classroom management strategy to employ.

Time-out. Time-out involves removal from positive reinforcement for a period of time (Goldstein, Harootunian, \& Conoley, 1994). More specifically, with exclusionary time-out a child is physically removed from positively reinforcing items and activities for a specified period of time when that child engages in inappropriate behavior. Time-out is a commonly used discipline technique in the classroom. In fact, $70 \%$ of teachers reported using time-out to manage disruptive classroom behavior (Zabel, 1986). Time-out has been found to be effective in 
decreasing inappropriate behavior. In fact, time-out was used to decrease aggressive behaviors (Jones, Sloane, \& Roberts, 1992) as well as noncompliance (Handen, Parrish, McClung, Kerwin, \& Evans, 1992) of children in Head Start classrooms. Time-out also has been effective in decreasing obscene vocalizations in an elementary school student (Lahey, McNees, \& McNees, 1973). Although research has supported the effectiveness of time-out, there are several disadvantages to implementing time-out in the classroom. Many hours of training are required in instructing teachers in the use of time-out procedures in the classroom (Barkley, 1997; HembreeKigin \& McNeil, 1995; \& Greene, Kamps, Wyble, \& Ellis, 1999). Another disadvantage of timeout is students may either refuse to go to or escape from time-out (McNeil, Clemens-Mowrer, Gurwitch, \& Funderburk, 1994). The teacher may have to physically place the child in time-out. Thus, other students in the classroom as well as the teacher may be at risk for harm when aggressive children do not accept or escape from time-out. In addition, other students in the classroom may become frightened and distracted when a child screams while in time-out. The implementation of time-out may decrease time devoted to learning activities, thus impacting preschool children's school readiness. Therefore, teachers may seek an alternative strategy to manage disruptive classroom behavior.

Response Cost. Response cost is a behavior management strategy that has been used in classroom settings. Response cost is the removal of secondary reinforcers (e.g., tokens, chips) contingent upon engaging in targeted inappropriate behavior. Response cost is implemented to decrease the probability of future occurrences of the inappropriate behavior (Schloss \& Smith, 1994). With response cost, a child might lose one token for each incidence of noncompliance. After a specified period of time, tokens can be exchanged for rewards (e.g., stickers, activities). Response cost can be beneficial for use in the classroom. Although time-out may require a 
hands-on approach at times, response cost allows the preschool teacher to manage disruptive behavior without physical contact with the student thus providing a safe way to decrease unwanted behavior. Negative consequences generally can be administered without providing much attention to the child's misbehavior. Therefore, the misbehavior should decrease as the behavior is not reinforced by the teacher. With response cost procedures punishment can be administered quickly and the child does not have to be removed from ongoing activities (Reynolds \& Kelley, 1997). Therefore, response cost allows for the implementation of punishment without much disruption in the classroom. Teachers can easily learn and implement response cost in the classroom (Sarafino, 2001). In addition, response cost procedures easily can be made developmentally appropriate and understood by young children (Reynolds \& Kelley).

Response cost has been an effective strategy in decreasing undesirable behaviors in academic settings. For example, response cost was used with out-of-seat behavior in elementary school children. The children lost points contingent upon getting out of the seat. Points later could be exchanged for rewards. The out-of-seat targeted behavior was suppressed following the implementation of response cost (Wolf, Hanley, Lachowicz, \& Giles, 1970). McNamara (1971) used response cost strategies to modify both teacher and student behaviors. The teacher earned points (exchangeable for alcoholic beverages) contingent upon withholding attention for negative behaviors. Attention provided by the teacher for inappropriate student behavior was decreased. Response cost also was used in this study to effectively decrease the amount of disruptive behavior exhibited by the students.

A response cost treatment package was found to be effective in decreasing aggressive behavior in preschool children. Reynolds and Kelley (1997) implemented a response cost procedure with four preschoolers (ages 3 to 5 years) who were frequently engaging in aggressive 
behavior and were referred to treatment for these problematic behaviors. A multiple baseline design across subjects was used to examine the effectiveness of this program. Each child had a "Good Behavior Chart" that contained five smiley faces. Smiley faces were removed by the teacher contingent upon child aggressiveness. Prior to removing the smiley face, the teacher would inform the child of the removal and give a brief explanation of why the smiley face was being removed. After being observed for approximately 40 minutes, the child would receive a reward (e.g., being teacher's helper, sticker) if at least one smiley face remained on the board. All smiley faces were replaced on the board before the next observation period. If the child had at least four or five days in which at least one smiley face remained, that child could choose a prize from a surprise grab bag. Results showed a drastic decrease in aggressive behaviors in all student participants. The teachers rated this procedure as a highly acceptable treatment. More specifically, the teachers indicated the response cost package was easily and quickly implemented in the classroom and was a successful and appropriate strategy for managing aggression in academic settings. In addition to teacher satisfaction, the students who participated in the study also favored the response cost package.

Although research supports response cost as an effective treatment approach, response cost procedures have disadvantages as well. An important limitation of a response program is the possibility of losing all tokens for inappropriate behavior. Thus, problem behaviors may increase in frequency if the consequence of token loss is no longer an option. Therefore, response cost programs may require the addition of back-up consequences to be utilized with problem behaviors once all tokens have been expended (Sarafino, 2001). Response cost is a strategy that is negative in nature. Consequences (e.g., loss of tokens) are given for inappropriate behavior and no reinforcement (e.g., praise, stickers) is given for instances of appropriate behavior. The 
teacher attends to disruptive behaviors in the classroom while prosocial behaviors may receive little or no attention. For example, a child shares toys with classmates; says, "Thank you;" helps another child find crayons, and throws a block on the floor. With response cost, the child would lose a token for throwing the block while no reinforcement is provided for the many positive behaviors exhibited. Thus, children may learn behaviors to avoid, but may fail to learn what behaviors are desirable. Misbehavior may be decreased, but the child may not have a repertoire of positive behaviors to replace the inappropriate behaviors that were extinguished. Positive behavior support focuses on teaching adaptive behaviors to individuals who exhibit challenging behaviors as opposed to punishing these challenging behaviors (Horner, Dunlap, Koegel, Carr, Sailor, Anderson, Albin, \& O’Neill, 1990). The positive behavior support movement concentrates on teaching a repertoire of adaptive behaviors that individuals will engage in to obtain outcomes previously obtained by exhibiting challenging behaviors. In addition, Head Start focuses on positive ways to help children and promote positive emotional growth (Kupersmidt, Bryant, \& Willoughby, 2000). Response cost may not be a very acceptable classroom management strategy in Head Start because response cost only punishes negative behaviors.

Token Economies. Unlike response cost, token economies focus on positive behaviors. Token economies involve distributing tokens (e.g., chips, stickers) contingent upon engaging in specified desirable behaviors. The token then may be exchanged for rewards (e.g., playing a game, cookie) (Sarafino, 2001). Token economies generally consist of thee characteristics. First, token economies utilize a group implementation as opposed to individual implementation. Second, token economies are used to modify a variety of behaviors. Finally, token economies generally are comprised of various consequences for target behaviors. These three 
characteristics; however, are not required to label a behavior modification program as a token economy. In fact, characteristics, often times, differ from token economy to token economy. Sarafino (2001) indicated that no absolute criteria exist in evaluating whether a program qualifies as a token economy.

Response cost and token economy programs differ significantly from each other. Whereas response cost procedures involve the removal of tokens contingent upon inappropriate behavior, token economies involve obtaining tokens contingent upon appropriate behavior that may be exchanged for rewards. However, token economies frequently include components of a response procedure (Goldstein, Harootunian, \& Conoley, 1994; Sarafino, 2001). For example, tokens are earned for appropriate behavior and removed for inappropriate behavior. From this point forward, token economies will be discussed with the inclusion of response cost procedures, unless otherwise indicated.

Token economies are beneficial procedures to use in the management of classroom behavior. Tokens may be administered quickly and easily without much disruption to the class (Goldstein, Harootunian, \& Conoley, 1994). Punishment for inappropriate behavior may be delivered without physical contact between the teacher and student. The teacher simply can remove a point or token for misbehavior. In addition, punishment can be administered without providing much negative attention to the child engaging in the inappropriate behavior. The child's disruptiveness receives little attention and therefore is not reinforced. Token economy procedures easily can be made developmentally appropriate for preschool-aged children (McNeil \& Filcheck, 2001). Finally, token economies may coincide with Head Start philosophies more than response cost procedures. Token economies require teachers to attend to and reward desirable behavior. Thus, token economies may promote a more positive classroom atmosphere 
and obtain higher teacher satisfaction ratings than response cost procedures. This focus on positive behaviors overlaps with Head Start's emphasis on positive techniques to help young children.

The effectiveness of token economies in managing child behavior in the classroom has been well documented. Token economies have been found to be effective in nursery school classrooms with children with mental retardation (Baker, Stanish, \& Fraser, 1972). The group of children who received the intervention displayed more inappropriate behavior during baseline than the control group. However, when the token economy was implemented in the experimental group, these children's inappropriate behavior decreased to an average level below that of children in the control group. The number of time-outs was not reported.

Token economies also have been found effective in grade school classrooms. Anhalt, McNeil, and Bahl (1998) implemented the ADHD Classroom Kit (Kit; McNeil, 2000), a token economy with response cost, on a whole-classroom basis. This whole-classroom token economy involved every student in the first grade class participating in the same token economy and receiving the same rewards. Children were divided into groups of approximately four children in each group. Groups received labeled praises and happy faces contingent upon group members exhibiting appropriate behavior. Sad faces were received when group members engaged in inappropriate behaviors. At specified periods throughout the day, groups having more happy than sad faces received rewards. Results indicated that the target child (age 6) exhibited an increased amount of appropriate and on-task behavior during the implementation of the Kit as compared to regular classroom management strategies. In addition, the teacher and students in the classroom reported high satisfaction with the Kit.

Bahl, McNeil, Cleavenger, Blanc, and Bennett (2000) examined the effectiveness of the 
Kit in two first-grade classrooms with 6 participants. Results indicated that the participants engaged in more appropriate and on-task behaviors when the Kit was used as compared to the school-wide discipline procedure. Teachers and students also reported high satisfaction with the Kit, and teachers indicated the classroom environment was less disruptive when the Kit was used.

Token economies have been used successfully in preschool classrooms as well. A token economy with no response cost was implemented to increase amounts of cooperative play. Targeted children included those who played aggressively or were withdrawn (Wolfe, Boyd, \& Wolfe, 1983). These three preschool children received a token (e.g., sticker placed on a chart) for each minute they engaged in cooperative play (e.g., sharing an activity) with peers for up to 15 minutes. Tokens earned could be exchanged for 10 minutes of outside recreation time. The amount of cooperative play these children engaged in increased by more than $50 \%$ when compared to baseline levels. The number of time-outs received also decreased as compared to baseline levels. Children engaged in cooperative play in the afternoon even when the token economy only was implemented in the morning. In addition, cooperative play remained elevated when the token economy was discontinued.

Swiezy, Matson, and Box (1992) implemented a token economy (i.e., The Good Behavior Game) in a preschool classroom where children received tokens and verbal praise for compliance while instances of noncompliance were ignored. Children who achieved the preset criterion of tokens received an edible reward. Compliance significantly improved in children participating in the token reinforcement program when compared to compliance levels at baseline.

A token economy was implemented to an entire class of children who exhibited emotional disturbance (O’Leary \& Becker, 1967). Every 20 minutes the teacher wrote a rating on a pad 
located on each child's desk. These ratings could be exchanged daily for rewards. Following the implementation of this token economy, the average amount of disruptive classroom behavior decreased from $76 \%$ during baseline to an average of $10 \%$ during the token economy condition. Occurrences of disruptive behavior continued to remain low despite lengthening the delivery of the rewards to every four days.

The Level System. McNeil and Filcheck (2001) developed a token economy with response cost, the Level System, for use on a whole-class basis with preschool-aged children (see Appendix A). The Level System is considered a token economy as indicated by the three general characteristics of a token economy (Sarafino, 2001) previously discussed. The Level System consists of a board with seven levels. The three levels at the top of the board comprise the "sunny zone." The sunny zone includes pictures of sunshines with smiley faces. The sunshine pictures get increasingly larger from the bottom to the top sunny level. The bottom three levels comprise the "cloudy zone." The cloudy zone has pictures of storm clouds. The pictures contain more and larger clouds in the lower cloudy levels than in the upper cloudy levels. Between the sunny and cloudy zones is the "neutral zone." Each child in the class is assigned a shape (e.g., truck, boat, heart) with that child's name on the shape. All shapes are placed in the neutral zone prior to the beginning of the reward period.

When the reward period begins, children receive consequences for both appropriate and inappropriate classroom behavior. More specifically, when the child engages in appropriate behavior the teacher provides a specific verbal labeled praise (e.g., "Thank you for coming to circle time.") and moves the child's shape up one level in the sunny zone on the board. However, if the child engages in inappropriate behavior, a warning is given to the child before the child's shape is moved down a level. For example, the teacher would hold up two fingers and say to the 
child, "You have two choices. You can either come to circle time or you will move down one level." If the child does not comply following the warning, the teacher then will move the child's shape down one level. Teachers should use a boring, robotic voice when giving a warning to ensure that limited attention is provided for child negative behavior. Teachers also should provide feedback to students (e.g., praise, warnings) often and immediately following the behavior.

Following a specified period (e.g., story time), children whose shape is in the sunny zone receive a reward (e.g., graham cracker, act like your favorite zoo animal). All children in the sunny zone receive the same reward making it easily dispensed to numerous children. The children who did not earn the reward continue engaging in regular classroom activities and stations (e.g., blocks, art) while the other children receive their reward. Children who received the reward return to the regular classroom activities after the reward is completed. The rewards are printed on individual cards (Appendix B). The teacher draws from this stack of cards to determine the reward. The teacher then puts that card aside as each reward must be used before any rewards can be reused. This procedure may help to keep children motivated toward earning the reward as they do not know what reward they are working for until the reward is dispensed. Rewards are distributed approximately two times in both the morning and afternoon. Rewards are given frequently because children with behavior problems require feedback and consequences often to help them stay on-task and behave appropriately (Hembree-Kigin \& McNeil, 1995).

The rewards are given, and each child's shape is returned to the neutral zone. The reward period begins over to allow all students the opportunity to earn the next reward. All children then have a clean slate and a chance to start over and earn the next reward. This procedure may help 
keep children with behavior problems motivated as they are provided numerous chances to obtain the reward.

The Level System is a new program and only a small amount of literature exists supporting its effectiveness. The Level System was implemented in one preschool classroom using an ABABCC' single-subject design with follow-up, where "B" is the Level System (Filcheck, Greco, Bernard, \& McNeil, in press). Both child and teacher behaviors were affected by the implementation of the Level System. The mean frequencies of inappropriate behavior per child per minute decreased from .45 during the baseline condition to .29 when the Level System was implemented. The amount of praise provided by the teacher increased while using the Level System. More specifically, labeled praises increased from .07 in baseline to .50 during use of the Level System while unlabeled praises were .25 in baseline and .63 while the Level System was in place. In addition, the amount of criticisms the teacher used decreased with the use of the Level System. The teacher was giving an average of 1.09 criticisms per minute during baseline. The number of criticisms per minute decreased to .96 during the Level System condition. Following this study the teacher chose to implement the Level System in the classroom.

Filcheck (2003) investigated the effectiveness of the Level System in two preschool classrooms. Disruptive behavior decreased more during the implementation of the Level System in children as compared to strategies used by the teachers prior to treatment implementation. However, treatment effects did not reverse. Rates of appropriate behavior did not vary much across conditions. For example, the mean frequency of appropriate behavior for all participants increased approximately $21 \%$ when the Level System was implemented, decreased $7 \%$ when the Level System was removed, increased approximately $8 \%$ when the Level System was implemented again, and decreased almost $7 \%$ at follow-up. The teachers reported fewer time- 
outs when the Level System was used as compared to typical classroom behavior management techniques. In addition, the teachers reported high satisfaction ratings for the Level System. However, the teachers did not choose to implement this program at follow-up. Maintaining treatment integrity was an obstacle in this study. The teachers frequently needed feedback to implement the program accurately or consistently.

Token economies may be beneficial in decreasing disruptive classroom behavior. However, token economies have some drawbacks as well. Token economies may require teachers to obtain thorough training in the token economy's implementation. In addition, using token economies for classroom management may require large amounts of time from the teacher. For example, the teacher must monitor the token economy to ensure children are receiving tokens for appropriate behavior. In addition, time is required to exchange tokens for rewards. Thus, teachers may prefer response cost procedures, which are easier to implement and require less time, but future research is needed to examine this issue.

In sum, behavior problems in the classroom continue to be an area of concern for teachers. Many strategies have been employed in the classroom to aid in behavior management. Time-out is one of the most commonly used behavior management technique in academic settings. Research has supported the effectiveness of time-out in decreasing inappropriate classroom behaviors (Handen, Parrish, McClung, Kerwin, \& Evans, 1992; Jones, Sloane, \& Roberts, 1992; \& Lahey, McNees, \& McNees, 1973). Response cost also has been used successfully in the classroom to extinguish undesirable behaviors (McNamara, 1971; Reynolds \& Kelley, 1997; \& Wolf, Hanley, Lachowicz, \& Giles, 1970). Numerous research studies support the efficacy of token economies for use with young children with behavior problems (Baker, Stanish, \& Fraser, 1972; O’Leary \& Becker, 1967; Swiezy, Matson, \& Box, 1992; \& Wolfe, Boyd, \& Wolfe, 
1983). The Level System (McNeil \& Filcheck, 2001), an example of a token economy, has been used successfully to decrease disruptive behavior in preschool children. Though these strategies have been effective in managing classroom behavior, disadvantages must be considered when determining which strategy to employ in the classroom. At this point, few investigations have addressed the relative effectiveness and acceptability of these programs for classroom management of preschool children.

\section{Comparing Response Cost and Token Economy Procedures}

Research has supported the effectiveness of both response cost and token economy procedures in decreasing disruptive behavior in academic settings. However, both procedures employ different strategies to manage classroom behavioral problems. Therefore, it is important to examine research comparing the relative effectiveness of these two procedures.

Iwata and Bailey (1974) used a reversal design to compare reward and cost token systems with special education children in elementary school. Fourteen children (mean age of 10 years) were chosen to participate based on teacher report of high levels of off-task and disruptive behavior. The children were divided into two groups of seven each. The children's behavior was observed every morning for three months during math class. Group R-C (reward-cost) earned tokens for appropriate behavior while Group C-R (cost-reward) began the day with 10 tokens, which were removed for inappropriate behavior. When a signal was heard, the teacher would give the students in the R-C group who were behaving appropriately a token. Students in the C-R group would lose a token at this time contingent upon misbehavior. At the end of the period, students who met a preset criterion would receive a snack. The response cost and token economy procedures were then removed for seven sessions and then reinstated. When the program was reinstated, however, the groups were reversed. For example, the group that earned tokens 
previously would now comprise the cost group while the group that previously comprised the cost group would earn tokens for appropriate behavior. Results indicated that both programs were equally effective in decreasing off-task behavior and the violation of the teacher's rules. Mean percent off-task behavior returned to a level similar to baseline during the reversal phase. During baseline, group means for off-task behavior were 30 for the R-C group and 32 for the C$\mathrm{R}$ group. However, during the treatment phase rates of off-task behavior decreased ( $\mathrm{R}-\mathrm{C}=10$; $\mathrm{C}$ $\mathrm{R}=6$ ). When the treatments were removed, mean off-task behavior increased to rates similar to baseline means ( $\mathrm{R}-\mathrm{C}=29 ; \mathrm{C}-\mathrm{R}=24)$. The number of mathematic problems completed more than doubled for the group earning tokens while the cost group only showed a small increase in problems completed. Following the completion of the study, students were permitted to choose the program they preferred. However, no pattern was found in the children's choice. Teacher and parent satisfaction were not assessed in this study. Teacher behavior also was affected in this study. The teacher provided more statements of approval to students who were in the reward-cost group than to children who were in the cost-reward group.

Sullivan and O'Leary (1990) also compared the effectiveness of both response cost and token economy procedures. Participants were ten children (ages 6 to 9 years) attending summer school who were reported by their teachers to have academic difficulties and/or behavior problems. Children were observed daily for 40 minutes during reading and language and math class. In the morning, the rewarding program was implemented during math class while the response cost program was implemented in the reading class. Programs were reversed in the afternoon in that the math class utilized the cost program while the reading class had the reward program. The reward program consisted of receiving teacher verbal praise and tokens that could be exchanged for rewards contingent upon appropriate behavior. However, in the response cost 
program, inappropriate behavior was followed by teacher verbal reprimands and the loss of tokens. Both programs were highly and equally effective in reducing the amount of off-task behavior. More specifically, average percent on-task behavior in the baseline condition was approximately $60 \%$, but then increased to approximately $85 \%$ when both programs were in effect. However, rates of on-task behavior differed between the two programs when the programs were faded from use. When the response cost program was faded, improvements in ontask behavior were maintained for all students participating in this program. However, half of the children who participated in the reward program did not maintain treatment effects when the program was faded from the classroom. Measures of student, parent, and teacher satisfaction were not included in this study.

The effectiveness of response cost and token economies in reducing disruptive behavior was examined with children with Attention-Deficit/Hyperactivity Disorder (ADHD; McGoey \& DuPaul, 2000). Participants included four children (4-5 years of age) in preschool who had been diagnosed with ADHD. In addition, three children identified by their teachers as displaying typical behavior served as control participants. Children were observed in their preschool classroom for 20-minute observation periods occurring at least three times each week. In addition, teachers completed questionnaires on the children's behavior as well as a treatment acceptability scale. The study used a single subject reversal design in two classrooms to compare behavior at baseline (A), token economy (B), and response cost (C). Half the participants received the interventions in $\mathrm{ABACABAC}$ order, while the experimental design for the other participants was ACABABAC. The final condition of the study included the intervention the teacher selected. During the token economy condition, students earned small buttons for appropriate behaviors (e.g., no talking when teacher is speaking). Five of these small buttons 
could be exchanged for one large button. Three large buttons were required to earn the reward at the end of the school day (e.g., stickers). During the response cost procedure, all buttons (5 small and 3 large) were placed on a chart at the beginning of the school day. Buttons were removed contingent upon inappropriate behavior (e.g., not following classroom rules). If the child retained at least three buttons at the end of an activity, the large button remained on the board. The child earned the reward if all three large buttons were retained at the end of the day. Both programs were effective in reducing disruptive behavior exhibited in the classroom. In addition, teachers rated both procedures as acceptable treatments for use in academic settings. However, the response cost received a higher acceptability rating by the teachers than the token economy. In addition, both teachers chose to implement the response cost in their classrooms following the study. McGoey and DuPaul suggested this preference may be due to one specific component in

the token economy. Teachers must continually scan the classroom for appropriate behaviors and immediately reward those behaviors. Catching these children engaging in appropriate behaviors requires much teacher time and effort that is difficult to provide in large classrooms. The response cost procedure does not appear to require much time or effort to implement in large classrooms.

\section{Summary}

In sum, classroom behavior management has become a topic of concern for teachers. Therefore, strategies that effectively manage behavior in the classroom are imperative. Time-out is the most commonly used behavior management procedure utilized in the classroom today. However, removing a child for time-out may interfere with academic progress and refusal of time-out may require the teacher to implement a hands-on approach. Response cost and token economy procedures are additional techniques that are implemented to modify behavior and 
involve a hands-off approach to behavior management. Response cost procedures involve the removal of tokens contingent upon engaging in inappropriate behavior while in token economies tokens are earned for appropriate behavior and can be exchanged for rewards. The response cost and token economy procedures may be implemented in academic settings without causing much disruption in the classroom. Research studies have compared these two procedures and found that both are effective in reducing undesirable behaviors (Iwata \& Bailey, 1974; McGoey \& DuPaul, 2000; \& Sullivan \& O’Leary, 1990). However, no studies were found examining the relative efficacy and acceptability of response cost and token economy procedures in Head Start classrooms.

Purpose of the Proposed Study

The purpose of the current study was to examine and compare the efficacy of three behavior management strategies implemented in a Head Start classroom with three children with disruptive behavior. The three strategies were the behavior management techniques currently being used by the teacher (i.e., baseline), response cost, and the Level System (i.e., token economy). Specifically, the present study used an ABACA single-subject withdrawal design with follow-up. The current study examined whether the rate of inappropriate behavior exhibited by the three children decreased during experimental phases (i.e., response cost and the Level System) as compared to the behavior management techniques the teacher was using in the classroom prior to treatment implementation (i.e., baseline and withdrawal phases). The efficacy of the three behavior management strategies was examined by behavioral observations as well as teacher report of student behavior. Treatment satisfaction was assessed for the teacher and parents and children who had given consent to participate in the study. Teacher satisfaction was examined by teacher report on a treatment acceptability measure (i.e., Intervention Rating 
Profile; IRP), in addition to considering the treatment the teacher chose to implement in the classroom at the follow-up assessment. Parent satisfaction was examined by parent report on the IRP as well as considering the treatment the parent preferred to be implemented in the child's classroom. Child satisfaction was examined by considering the treatment the child preferred to be implemented in the classroom. This study also examined whether teacher skill varied in the two treatment conditions. More specifically, behavioral observations were conducted to examine the number of praise statements and criticisms the teacher exhibited in each condition. Finally, the study examined the impact of the treatment conditions on teacher use of time-out.

The current study provided novel information to the existing literature on response cost and token economy procedures. Most research that has evaluated response cost and token economy programs with young children has been implemented with individual children. The current project implemented both a response cost program and token economy on a whole-class basis. In addition, no research was found comparing the efficacy of these two programs in a Head Start setting. Head Start is a federally funded program that provides services to preschoolaged children and their families. Children in Head Start are from low-income families and receive services that address physical health, social development, and developmental and emotional needs (Kassebaum, 1994; Kupersmidt, Bryant, \& Willoughby, 2000). Children from low-income families experience many factors associated with poverty (e.g., violent neighborhood conditions, family discord, parental depression, stress) that may put them at a greater risk for developing behavior problems than children from middle- or upper-income families (Kupersmidt et al.; Harden et al., 2000; McLoyd, 1990; Webster-Stratton, 1990). In fact, Kupersmidt et al. found that children enrolled in Head Start exhibited more physically aggressive behaviors than children enrolled in community daycare centers. Due to the risk of an elevated 
amount of behavior problems in Head Start classrooms than in daycare or preschool centers, efficacious behavior management programs must be used in Head Start classrooms to help decrease these problem behaviors. Research has found that behavior problems at a young age are associated with a variety of difficulties later in life. Therefore, implementing behavior management strategies with young children in Head Start may help prevent the stability of problems. In addition, no research was found comparing teacher, parent, and child satisfaction with classroom behavior management strategies. Classroom management programs may be more like to be implemented if there is high satisfaction with the program. The current study evaluated satisfaction with response cost and the Level System with teachers, parents, and children in one Head Start classroom.

Hypothesis one: Efficacy. It was hypothesized that the response cost and token economy procedures would be more effective than the strategies currently employed by the teacher in decreasing inappropriate behavior and increasing appropriate behavior. More specifically, the target children were expected to exhibit less inappropriate behaviors when the response cost and the Level System were implemented than when the teacher was using the strategies utilized before the study. Further, it was hypothesized that both the response cost and token economy procedures would provide similar results. In other words, both procedures would be similarly efficacious in reducing problem behaviors and increasing desirable behaviors (Iwata \& Bailey, 1974; McGoey \& DuPaul, 2000; \& Sullivan \& O'Leary, 1990).

It was hypothesized that the number of time-outs the target children received would decrease in the treatment conditions (i.e., response cost and the Level System) as compared to the baseline/withdrawal conditions. This result was expected because the teacher was implementing behavior management techniques during the treatment phase that included 
consequences for inappropriate behavior. Consequences could be administered easily with the response cost and Level System allowing time-out to be used only as a last resort. However, during the baseline/withdrawal conditions time-out was be the primary consequence for inappropriate behavior.

Hypothesis two: Satisfaction. It was expected that the teacher, teacher's aide, and class grandparent would report more satisfaction for the two treatment programs (i.e., response cost and the Level System) than with the strategies used in the classroom prior to the study. This result was expected because research has found high satisfaction ratings for both procedures among teachers (McGoey \& DuPaul, 2000; Reynolds \& Kelley, 1997; Witt, Elliott, \& Martens, 1984). It was further hypothesized that the teacher would report more satisfaction with and prefer the response cost procedure over the token economy. This result was expected because previous research found that teachers were more satisfied with response cost procedures as opposed to token economy procedures possibly due to greater amounts of time involved in implementing token economies as opposed to response cost programs (McGoey \& DuPaul). It was expected that parents would report more satisfaction with and prefer the token economy procedure over the response cost. This result was hypothesized because the token economy involved reinforcing appropriate behavior and implementing minor consequences (e.g., moving down one level) for inappropriate behavior, while the response cost only involved consequences (e.g., moving shape down) for undesirable behavior. Therefore, it was hypothesized that the parents would choose the token economy because this program focused on and reinforced positive behaviors. Finally, it was expected that the children would choose the token economy as opposed to the response cost program. As with parents, it was expected that children would choose the token economy because this program was more positively focused than the response cost. 
Hypothesis three: Teacher skill. It was hypothesized that the number of praises and criticisms the teacher exhibited would differ between conditions. More specifically, it was hypothesized that the teacher would use more criticisms and fewer praise statements in the response cost and baseline/withdrawal conditions than in the Level System condition. This result was expected because teachers were trained to reduce the number of criticisms used and increase the number of praises they gave children in the Level System condition. However, these skills were not targeted during the response cost procedure. In addition, Iwata and Bailey (1974) found that teachers engaged in more approval statements with children participating in the token economy procedure than with children participating in the response cost program.

Method

\section{Setting}

Data were collected in one Head Start classroom in southwestern Pennsylvania. All phases of the study were conducted in the children's regular classroom with the primary teacher and teacher's aide. However, data were not collected when the primary teacher or one of the participants was absent. The teacher, teacher's aide, and class grandparent received payment for participation in the study (i.e., $\$ 400, \$ 200$, and $\$ 100$ ). The class grandparent was an adult who volunteered time in the Head Start classroom. The class grandparent assisted the teacher and teacher's aide with classroom activities (e.g., art, rest period).

\section{Participant Selection}

Children must have had parental informed consent (i.e., parent signed and returned consent form) to be considered for participation in the study. Participants for the treatment component of this study were 3 children between the ages of 3 and 5 who were enrolled in the Head Start program. Participants were identified by the teacher as exhibiting disruptive behavior based on 
the teacher's report on the Conners' Global Index (CGI, Conners, 1997; Appendix C). More specifically, the teacher identified 5 children with informed consent the teacher considered to be exhibiting disruptive behavior in the classroom and completed a CGI for each of these 5 children. Three children with the most similar CGI scores were chosen to participate in the study. All three child participants were four years old. Two children participated in the entire study, but Damon withdrew from Head Start prior to the follow-up condition. Therefore, follow-up data only were collected for Ruby and Mitch. The teacher and teacher's assistant were aware of the identity of target participants as they completed CGI measures on these three children throughout the study. For the satisfaction component of the study, all children and parents with informed consent participated, as well as the teacher and teacher's aide. However, few parents and children with informed consent participated, as the study continued into the next school year.

\section{Measures}

\section{Participant Selection Measure}

Conners' Global Index (CGI). The CGI contains 10 of the 39 items from the Conners' Teacher Rating Scale-39 (Conners, 1969) including the restless/impulsive and emotional lability factors. The CGI assesses hyperactivity and general child pathology, including disruptive behavior. Behaviors are rated on a 4-point Likert scale from 0 (not at all) to 3 (very much). The CGI has been found to demonstrate an interrater agreement of .85 and internal consistency of .90 (Margalit, 1983). Epstein and Nieminen (1983) reported an interrater reliability of .70 as well as a teacher interrater reliability of .87 for the CGI. The teacher completed a CGI for the three participants before the study, following the termination of each treatment condition, and at the follow-up evaluation.

Treatment Efficacy Measures 
Revised Edition of the School Observation Coding System (REDSOCS). The REDSOCS (Jacobs et al., 2000) is a coding system used to rate observed behavior of both students and teachers in the classroom setting. The REDSOCS has been revised from the School Observation Coding System (SOCS) developed by McNeil, Eyberg, Eisenstadt, Newcomb, and Funderburk (1991). The SOCS was revised because this coding system was not time efficient. More specifically, the SOCS included a 10 -second observe interval followed by a 5 - to 10 -second interval to record information. Although the REDSOCS maintained the 10-second observe intervals of the SOCS, the REDSOCS includes immediate marking of behaviors following the 10-second observe interval as opposed to marking behaviors during 5-10-second intervals as the SOCS does. The REDSOCS includes pauses in observations as the end of each 60 -second period before observing the next child instead of following each 10-second interval like the SOCS. The SOCS provided operational definitions of common classroom behaviors and categorized these behaviors into 3 types of behaviors: Appropriate vs. Inappropriate, On-task vs. Off-task, and Compliance vs. Noncompliance. The REDSOCS also uses these three categories of behavior; however, this study only assessed the Appropriate vs. Inappropriate category (see Appendix D for category definitions). The On-task vs. Off-task category was omitted because Head Start classrooms tend to include an unstructured setting where children are permitted to perform tasks and complete activities at different stations throughout the classroom. Children frequently are permitted to change stations and are not required to complete certain tasks before moving to new stations. In addition, children are not required to be on task during teacher-lead activities (e.g., storytime, singing songs); however, children are required to behave appropriately in the classroom during all activities. Due to the unstructured nature of the Head Start classrooms, the behavior of "cheating" in the inappropriate category was not coded. In addition, 
the Compliance vs. Noncompliance category was omitted in the present study. However, acts of defiance were coded under the inappropriate category because defiance can be annoying or disruptive to the target child, the teacher, or other children, as defined by the inappropriate behavior category. Child behaviors were coded during 10-second intervals to obtain a total percentage for each category during that observation.

The teacher's behaviors recorded were unlabeled praise, labeled praise, and criticism. Definitions for these terms (Appendix E) were adapted from the Dyadic Parent-Child Interaction Coding System - Second Edition (DPICS-II; Eyberg, Bessmer, Newcomb, Edwards, \& Robinson, 1994). Each unlabeled and labeled praise and criticism was coded regardless of which child the teacher directed the statements toward. Teacher behaviors were coded during 10 -second intervals to obtain a total percentage of each behavior during that observation. The box on the coding sheet that corresponded with the type of statement the teacher exhibits was marked. For example, the "Labeled Praise" box was marked if the teacher gave any labeled praises during that interval. The interval box was marked only once regardless of whether the teacher gave one or five labeled praises during that interval.

The REDSOCS was used to record observed behavior in the classroom. The study used an interval coding system. Behavior for the target participants and teacher were observed concurrently during 10-second intervals and recorded concurrently throughout the observation interval. For example, the behaviors of Ruby and the teacher were coded concurrently during certain intervals. However, the behavior of each child was coded for 6 consecutive intervals. For example, Ruby was observed for 6 consecutive 10-second observations. Then Damon was observed for 6 consecutive 10-second observations and then Mitch was observed for another 6 consecutive 10-second intervals and so on. The teacher was observed during every interval 
during the observation period. Observations occurred for approximately 40 minutes during structured morning activities (see Appendix F for coding sheets). Jacobs et al. (2000) report good psychometric properties of the REDSOCS. Interobserver agreement for the Appropriate Behavior and Inappropriate Behavior categories were .85 and .83 respectively.

Teacher Rating of Child Manageability. The primary teacher completed a daily evaluation of the manageability of the classroom throughout the entire study. The teacher rated the level of classroom manageability on a 5-point Likert scale ranging from 1 (completely unmanageable) to 5 (completely manageable) (Appendix G). Information obtained from this rating was used to evaluate how manageable the classroom was during each condition of the study.

Time-Out Log. The primary teacher completed a daily time-out log (Appendix H) throughout the entire study. The teacher recorded the number of time-outs each participant received each day during the study. In addition, the teacher recorded why the child received a time-out and the length of each time-out received. Information obtained from this log provided data about the number of time-outs received by participants in each phase of the study and whether there were differences in the number of time-outs in different phases. These data provided information on the efficacy of the interventions in managing classroom behavior (i.e., response cost and Level System).

\section{Satisfaction Measures}

Intervention Rating Profile (IRP). The teacher, teacher's aide, and class grandparent completed the IRP (Witt \& Martens, 1983) following the termination of the baseline condition, each treatment phase of the study, and at the follow-up assessment. Also, the primary caregiver of the students with parental consent in the classroom completed the IRP once for each intervention (i.e., response cost and Level System) at the end of the study. The IRP is a 20-item 
questionnaire that assesses satisfaction with and acceptability of classroom interventions to manage children's behavior. Intervention items were rated on a 6-point Likert scale ranging from 1 (strongly disagree) to 6 (strongly agree) (Appendix I). Scores obtained on the IRP indicated level of acceptability. For example, a higher score on the IRP indicated more satisfaction or acceptability with the intervention. Research has found the IRP to be a reliable measure of treatment acceptability (.91) and sensitive to differences in the acceptability of diverse treatments (Witt, Elliott, \& Martens, 1984; Witt \& Martens).

Parent interview. Primary caregivers who agreed to participate in the study completed the parent interview once following the final withdrawal phase of the study. The parent interview was adapted from the original parent interview developed by Filcheck (2003). The parent interview contained 18 items that assessed acceptability of various aspects of behavior management strategies (Level System, response cost, time-out, and praise). The first 11 items of the interview were rated on a 6-point Likert scale ranging from 1 (strongly disagree) to 6 (strongly agree). The final 7 questions of the interview were open-ended to allow caregivers to expand on items and provide further information (Appendix J).

Parent and child treatment choice. Parents and children who agreed to participate in the study chose their treatment of choice following the final withdrawal phase of the study. The author explained the response cost and the Level System, using a script, to the parents and children. The order of presentation was randomly selected for each participant. Parents verbally indicated the treatment they would choose to be implemented in their child's classroom. Children rated both procedures (i.e., response cost and the Level System) on a smiley face scale where the faces ranged from "do not like this at all" to "like this very much." Also, children were asked to choose which system they liked best. Scripts of the procedures for both parents and children and 
the child smiley face rating sheet are in Appendix K.

\section{Treatment Integrity Measure}

Treatment Integrity. Treatment integrity was evaluated using a treatment integrity checklist for each treatment condition (Appendices $\mathrm{L}$ and $\mathrm{M}$ ) that was completed daily by one research assistant during both treatment phases. The integrity checklist evaluated if the teacher and teacher's aide were implementing the intervention accurately. Accurate implementation of the interventions was achieved if a score of $85 \%$ or higher was obtained on the treatment integrity checklist. If a score less than $85 \%$ was obtained on 2 consecutive days, data for those days were omitted from data analyses and both the teacher and teacher's aide were retrained in the accurate implementation of the intervention. Neither the teacher nor the teacher's aide required retraining in either treatment program (i.e., response cost and Level System). Once the teacher and teacher's aide obtained a score of $85 \%$ on the treatment integrity checklist, data collection began. The teacher and teacher's aide were aware that these integrity measures were completed, and feedback on their performance was provided daily.

\section{Behavioral Observation Measure}

Classroom coding system. One advanced undergraduate research assistant and one graduate research assistant collected data for the study. The research assistants were trained to code classroom behavior exhibited by the children (i.e., appropriate vs. inappropriate categories) as described in the REDSOCS (Jacobs et al., 2000; Appendix D) as well as those exhibited by the teacher (i.e., praise and criticism; Appendix E). The research assistants were trained using pre-recorded video tapes of preschool classrooms. Teachers, parents, and administrators provided prior consent to use these tapes for research and teaching purposes. Training continued until .75 Kappa was obtained for each research assistant and primary investigator on each 
behavior category coded for the teacher and students (e.g., labeled praise, unlabeled praise, criticism, appropriate, and inappropriate) on three consecutive training sessions. Upon obtaining the .75 Kappa criteria, the research assistants completed live coding of behaviors in the Head Start classroom for the study.

Interobserver agreement. Interobserver agreement data were collected for $25 \%$ of the observations in each design phase. Observations completed for interobserver agreement were randomly selected. If interobserver agreement were below .75 Kappa, data collection was postponed, and the research assistants were retrained until .75 Kappa was obtained between the research assistants' and the author's coding. Interobserver agreement remained at or above .75 Kappa, and no retraining was required for either research assistant. The research assistants were unaware of the study's hypotheses. Average interobserver agreement Kappas for inappropriate behavior were $.97(.96-.98)$ for baseline, $95(.93-1.00)$ for response cost, $.99(.97-1.00)$ for the first withdrawal phase, and 1.0 for the Level System, second withdrawal, and follow-up phases. Average Kappas for labeled praises were $.81(.75-.86)$ for baseline, $.93(.80-1.00)$ for response cost, $.89(.85-.92)$ for the first withdrawal phase, $.96(.91-1.00)$ for the Level System, .95 for the second withdrawal phase, and .88 for follow-up. Average Kappas for unlabeled praises were .90 for baseline, $.95(.80-1.00)$ for response cost, $.93(.86-1.00)$ for the first withdrawal, $.98(.95-1.00)$ for the Level System, .96 for the second withdrawal, and .93 for follow-up. Finally, average Kappas for criticisms were $.89(.86-.92)$ for baseline, $.95(.85-$ 1.00) for response cost, 1.00 for the first withdrawal, $.95(.85-1.00)$ for the Level System, and 1.00 for both the second withdrawal and follow-up phases.

\section{Procedure}

\section{Teacher Training}


Baseline data were collected prior to the implementation of the treatment phases. Following baseline data collection, the primary teacher, teacher's aide, and class grandparent were trained in the use of the response cost system. The author trained the teacher, teacher's aide, and class grandparent in the procedures of the response cost system during a 1-hour workshop. Then the author coached the teacher and teacher's aide in the classroom in the use of the response cost program until $85 \%$ treatment integrity was achieved. As the teacher and teacher's aide were the primary classroom instructors, the class grandparent received training, but not coaching in the treatment procedures. The training provided the class grandparent with knowledge about the behavior management techniques that were employed in the classroom. After the response cost and withdrawal conditions, the teacher, teacher's aide, and class grandparent received training in the use of the Level System, providing labeled praise, and avoiding critical statements during an additional 1-hour workshop provided by the author. Again, the author coached the teacher and teacher's aide in the classroom in the use of the Level System until $85 \%$ treatment integrity was achieved. The teacher and teacher's aide required one day of coaching for each program to achieve $85 \%$ treatment integrity. Data collection in experimental phases did not begin until treatment integrity had been reached. The teacher and teacher's aide were given feedback on treatment integrity throughout the study. Teachers could use time-out during all conditions of the study. The experimenter; however, did not discuss the use of timeout with the Head Start staff when training the staff in the use of the programs.

\section{Classroom Observations}

Observations were conducted for approximately 40 minutes during structured classroom activities (e.g., circle time, story time). Classroom behaviors were coded using the REDSOCS (Jacobs et al., 2000). Child observations were conducted in 10-second intervals and the children 
were observed in 60-second rotations during the approximately 40 -minute observation period for a total of 84 intervals per child. The primary teacher was observed continuously for 10 -second intervals for a total of 252 intervals. A single mark was given if there was any occurrence of criticism, labeled praise, or unlabeled praise. The research assistants coded appropriate and inappropriate student behaviors while coding teacher behaviors of verbal praise and critical statements (see Appendix F for coding sheets). The research assistants were cued to the student to observe and the behaviors to code during intervals by listening to an audiotape through headphones. For example, the assistants heard the following through the audiotape: "Damon. Observe." The research assistants then coded behaviors for student \#2 and the teacher. A dualjack audio system was used for reliability coding allowing both coders to hear the same audiotape.

\section{Experimental Conditions}

The current study uses a single-subject withdrawal design (i.e., ABACA) with a 6-week follow-up evaluation. The three conditions that were comprised in the design included: behavior management techniques currently employed by the teacher and teacher's aide (“A”), response cost ("B"), and the Level System ("C"). Each condition continued until data were stable. Stability criteria initially were to be based upon student inappropriate behavior. Due to difficulty in obtaining stability for child behavior and low frequencies of inappropriate behavior, stability criteria later were changed to teacher labeled praise. Teacher labeled praise data were chosen as stability criteria due to the stability of these data throughout the study. Stability was reached for conditions when at least 4 observations had been collected and no clear trends were observed for the final 3 observations of the phase. Upon withdrawal of the final withdrawal phase (condition "A"), the teacher was permitted to choose the behavior management techniques for use in the 
classroom. The 6-week follow-up assessment was conducted to determine which behavior management procedure the teacher was using in the classroom at that time. The teacher's choice of behavior management techniques was used to indicate teacher satisfaction with behavior management procedures. In addition to teacher's choice of techniques, student inappropriate behavior also was coded at the follow-up assessment to evaluate the efficacy of the chosen classroom procedure in managing student behaviors. The follow-up assessment phase of the study was conducted until stability in data was obtained with a minimum of four observations.

Teacher behavior management techniques currently employed. The primary teacher and teacher's aide used behavior management strategies they had been using in the classroom prior to the current investigation. The teacher and teacher's aide used these strategies in the first, third, and fifth phases. These phases were the baseline and withdrawal conditions of the study.

Response cost. The primary teacher and teacher's aide used the response cost procedure in the second phase of the study (Appendix N). This phase served as the first treatment phase ("B"). The response cost was used with all students in the classroom; however, data only were collected on the 3 participants with parental consent. The teacher explained the response cost procedure to the classroom with the author present to ensure the children understood the response cost. The response cost program contained a board with four levels. The first three levels had sunshines and comprised the "sunny zone" of the board. The bottom level had clouds and comprised the "cloudy zone" of the board. A shape was assigned to each child in the classroom. All children's shapes began in the top-most level of the board. Shapes were moved down one level contingent upon inappropriate classroom behavior (e.g., not following class rules, hurting). The teacher gave a verbal warning when a child engaged in inappropriate behavior (e.g., "You have two choices. You can either put the blocks away or your shape will be moved down one level."). If 
the inappropriate behavior continued, that child's shape was moved down one level. If a child hurt another individual or destroyed property, the teacher moved the shape down one level without a warning. The teacher was instructed to use the regular classroom management strategies when a child's shape was in the bottom-most level of the board and that child continued to engage in inappropriate behavior. After approximately 40-minute periods of time throughout the day all children whose shape was in the sunny zone of the board received the same reward (e.g., throw beanbag into a garbage can). Rewards were the same in the response cost and Level System conditions. Children whose shapes were in the cloudy zone of the board continued to engage in the regular classroom activities while the reward was administered. All shapes were replaced to the top-most level on the board and the children had another opportunity to obtain the next reward. The teacher completed a daily log on the number of rewards earned by the target children (Appendix O). If any child failed to earn a reward on two consecutive days, behavior expectations were lowered until that child earned at least one reward on two consecutive days. The teacher and teacher's aide had to maintain $85 \%$ treatment integrity. If treatment integrity was below $85 \%$, both the teacher and teacher's aide were retrained in the procedures. The teacher and teacher's aide did not require retraining on this program.

Level System. The primary teacher and teacher's aide used the Level System in the fourth condition of the study. The Level System was used with the entire classroom; however, data only were collected on the behaviors of 3 participants with parental consent and identified as exhibiting disruptive behaviors by teacher report. This phase was the second treatment phase ("C"). The teacher was instructed to use the regular classroom management strategies when a child's shape was in the bottom-most level of the board and the child continued to exhibit inappropriate behavior. The teacher explained the Level System to the children with the author 
present to ensure the children comprehended the Level System. The teacher completed a daily $\log$ on the number of rewards earned by each participant (Appendix O). If any child failed to earn a reward on two consecutive days, behavior expectations were lowered until that child earned at least one reward on two consecutive days. Again, rewards were the same for both the response cost and the Level System conditions and rewards were dispensed following periods of approximately 40 minutes of time. A treatment integrity of $85 \%$ had to be maintained by both the primary teacher and teacher's aide. If treatment integrity had fallen below $85 \%$, both the teacher and teacher's aide would have been retrained by the author in the accurate use of the Level System. The teacher and teacher's aide, however, did not require retraining on this program.

Results

\section{Efficacy}

The efficacy of techniques currently used in the classroom, response cost, and the Level System were examined by visual inspection of behavioral observation (i.e., REDSOCS), the CGI, Class Manageability Rating, and the Time-out Log. It was hypothesized that children would exhibit less inappropriate behavior during the two treatment conditions (i.e., response cost and Level System), and these two conditions would provide similar results in inappropriate behavior. It also was hypothesized that fewer time-outs would be administered during treatment conditions than baseline and withdrawal conditions.

REDSOCS. REDSOCS data collected from classroom observations were graphed following each observation. Specifically, data were graphed to inspect the percentage of inappropriate behavior intervals for all 3 student participants for each condition. Figure 1 represents the percent of intervals that Ruby, Damon, and Mitch exhibited inappropriate behavior. Results demonstrated a decreasing trend in inappropriate behavior throughout the study 
for each child. As inappropriate behavior did not return to baseline levels during withdrawal conditions, no conclusions about the efficacy of the treatment programs could be made based on inappropriate data. Ruby began taking stimulant medication concurrently with the implementation of the Level System further prohibiting conclusions about the efficacy of the program in decreasing inappropriate behavior for Ruby. In addition, data collection ceased for approximately three months following the response cost phase due to summer break.

CGI. CGI scores were obtained at baseline, after each treatment condition, and at followup. Raw scores on the CGI were converted to T-scores. Each child's CGI T-scores for the four conditions are represented in Table 1. T-scores between 45.00 and 55.00 are considered in the typical range of functioning while $\mathrm{T}$-scores above 60.00 are considered in the disruptive range.

CGI scores for Ruby were in the disruptive range throughout the study, but were in the borderline range at follow-up (i.e., baseline and response cost $=>90.00$, Level System $=89.00$, and follow-up $=59.00$ ). The teacher rated the behavior of Damon in the disruptive range for the baseline and response cost conditions (i.e., 63.00 and 62.00). This child's CGI score was in the typical range in the Level System condition (i.e., 44.00). Damon withdrew from Head Start, and CGI scores were not obtained during follow-up. CGI scores for Mitch were in the borderline and typical ranges (i.e., baseline $=57.00$, response cost $=58.00$, Level System $=54.00$, and followup $=46.00$ ). All children's CGI scores decreased throughout the study. Therefore, no conclusions could be made about the efficacy of the treatment programs by examining CGI scores.

Class Manageability Rating. The Class Manageability Rating was completed daily for all conditions. Class manageability was rated on a 5-point Likert scale where "1" was completely unmanageable and " 5 " was completely manageable. Figure 2 represents the daily class 
manageability ratings for each condition. Class manageability ratings appeared to remain stable from the baseline to response cost phases, increase from the response cost to the first withdrawal phase, and remain relatively stable for the remaining conditions. Mean class manageability ratings for each condition were as follows: 3.00 for baseline and response cost, 3.86 for the first withdrawal phase, 4.13 for the Level System, 4.10 for the second withdrawal condition, and 3.80 for the follow-up condition. As class manageability ratings did not fluctuate between conditions, but continued to increase, no conclusions can be made concerning the efficacy of the treatment programs based on class manageability data.

Time-out Log. The time-out log also was completed daily for all conditions of the study. On the time-out log, the teacher recorded the number of time-outs administered daily in the classroom. Figure 3 represents the daily number of time-outs for each condition. Visual inspection of the number of time-outs suggests continual decline in time-outs across conditions. Mean number of time-outs were as follows: 10.31 for baseline, 5.09 for response cost, 1.78 for the first withdrawal, 0.92 for the Level System, 1.20 for the second withdrawal, and 1.00 for follow-up. As in previous efficacy measurements, no conclusions can be made about the efficacy of the treatment strategies based on the number of time-outs.

\section{Satisfaction}

Teacher satisfaction was examined by comparing scores on the IRP for the current classroom strategies, response cost, and the Level System. The condition that yielded the highest IRP scores as well as the strategy chosen for implementation in the follow-up condition was considered the preferred classroom management technique. The teacher, teacher assistant, and class grandparent completed the IRP. The maximum score on the IRP is 120.00 , and higher scores are associated with more satisfaction and acceptance. The three staff's scores were 
averaged for each condition. The mean IRP scores were as follows: 112.00 (current strategies), 76.00 (response cost), and 77.33 (Level System). In addition, the teacher chose to employ the current strategies in the classroom at follow-up. The IRP scores and the teacher choice at followup suggest that the teacher was most satisfied with the strategies that were employed in her classroom prior to this study. Therefore, hypothesis two was not supported.

Parent satisfaction with the two treatment strategies (i.e., response cost, Level System) was determined by IRP scores, parental choice, and information obtained from the parent interview. More specifically, the strategy yielding the higher IRP score as well as the strategy chosen by the parents was considered the system with which the parents were most satisfied. It was hypothesized that parents would prefer the Level System to the response cost program. Two parents who had given consent to participate the following school year completed the parent satisfaction data. Five parents had consented to participate, but only two of those parents arrived to complete the satisfaction measures. Parents reported more satisfaction with the Level System as indicated by higher average IRP scores (i.e., 111.50 for Level System and 79.00 for response cost) as well as verbally choosing the Level System as the most preferred strategy. Results from the parent interview also indicated parental satisfaction with the Level System. Specifically, the mean score on the Likert rating questions was 65.50 out of 66.00 . On the final seven open-ended questions parents reported positive and negative aspects of the two treatment programs. A strength of the Level System included the ability of the shapes to move both up and down on the board. Parents reported no negative aspects of the Level System. Parents also reported no positive aspects of the response cost program. A negative aspect of the response cost included children receiving fewer chances to earn rewards. Hypothesis three was supported as parents reported more satisfaction with the Level System than the response cost. 
Student satisfaction was examined using a smiley face rating of the response cost and Level System strategies as well as child choice of strategy. More specifically, the system obtaining the highest smiley face rating as well as the strategy chosen by the student was considered the strategy yielding the most satisfaction. The smiley face ratings ranged from "like this very much" to "do not like this at all." It was hypothesized that the children would prefer the Level System over the response cost program. Only four children with parental consent returned to Head Start the following year. All four children chose the first smiley face rating (i.e., "like this very much") for the response system. For the Level System, two children chose the first smiley face. The remaining two children chose the second smiley face which represented "like this some." All four children rated the response cost strategy as the most preferred choice of intervention in the classroom. Therefore, hypothesis two was not supported.

\section{Teacher Skill}

Teacher skill was determined by examining the number of labeled praises, unlabeled praises, and criticisms used in each condition throughout the study. These teacher data were collected using the REDSOCS. Observation data were graphed following each observation. Specifically, data were graphed to inspect the percentage of intervals containing labeled praises, unlabeled praises, and criticisms for each condition. It was hypothesized that the teacher would use more criticisms and fewer labeled praise statements during the baseline/withdrawal and response cost conditions as compared to the Level System condition, as these skills were targeted during the Level System phase. Figure 4 represents the percent of observation intervals that the teacher used these skills. More specifically, teachers were taught to use labeled praises and avoid critical statements. Visual inspection of labeled praise data suggested an increase in the use of labeled praise in both treatment conditions as compared to baseline and withdrawal conditions. 
Labeled praise was used more often in the Level System condition than in any other condition of the study. In addition, the percentage of intervals that the teacher used these statements did not return to baseline levels in the second withdrawal or follow-up phases. The average percentages of intervals containing labeled praise statements for the conditions were as follows: 1.15 (baseline), 1.99 (response cost), 1.38 (withdrawal 1), 5.31 (Level System), 3.32 (withdrawal 2), and 3.04 (follow-up).

Visual inspection of unlabeled praise data suggested that the teacher used more unlabeled praise statements in the latter conditions of the study than the former conditions. The average percent of intervals with unlabeled praises were as follows: 2.34 (baseline), 4.69 (response cost), 9.48 (withdrawal 1), 7.12 (Level System), 7.64 (withdrawal 2), and 8.96 (follow-up). The average percent of intervals containing criticisms appeared to decrease throughout the study. The mean percentages were as follows: 6.66 for baseline, 5.28 for response cost, 6.43 for withdrawal 1, 3.5 for the Level System, 4.61 for withdrawal 2, and for 2.12 for follow-up. The teacher used the least critical statements in the follow-up condition as compared to all other conditions. As the teacher used more labeled praise during the Level System phase of the study, part of hypothesis three was supported. The teacher, however, used the least amount of criticisms during the follow-up condition; though it was hypothesized the teacher would use the least criticisms during the Level System phase.

\section{Discussion}

The current study examined the efficacy of three behavior management strategies (i.e., current strategies, response cost, and the Level System) used in a Head Start classroom. Efficacy was examined by direct observation of teacher (i.e., labeled praise, unlabeled praise, criticisms) and student (i.e., inappropriate behavior) behavior while the three behavior management 
strategies were utilized in the classroom. Satisfaction with these strategies also was examined for teachers, parents, and students. Teacher satisfaction was assessed by teacher report of satisfaction as well as the procedure the teacher chose to implement at follow-up. Parent and student satisfaction were examined by report of satisfaction as well as verbal choice of program.

No conclusions about treatment efficacy could be reached through inspection of student data, class manageability ratings, or number of time-outs. Inappropriate behavior and number of time-outs continued to decrease, while the class manageability ratings continued to increase throughout the study whether a treatment was implemented or not. These findings could be attributed to the following aspects. First, the teacher's behavior changed throughout the study. She used a greater number of praise statements and fewer critical statements as the study progressed. Similarly, the teacher in the study by Filcheck, Greco, Bernard, and McNeil (2003) used more praise and fewer criticisms throughout the study. The teacher's use of more positive interactions with the children may have reinforced child appropriate behavior. This carryover effect (Parsonson \& Baer, 1992) indicates that no functional control was obtained and limits the ability to draw conclusions about treatment efficacy. Second, teacher ratings of class manageability and number of time-outs administered could have been impacted by an increase in child appropriate behavior. In other words, teachers would have to administer fewer time-outs and would consider their classroom more manageable when children are following classroom rules.

Satisfaction data also were collected for teachers, parents, and students. Teachers preferred the strategies they had been using in the classroom prior to the implementation of this study to the two treatment programs. This finding both is consistent and inconsistent with previous research. Filcheck, Greco, Bernard, and McNeil (2003) also found that the teacher reported more 
satisfaction with current classroom strategies than the Level System. Research, however, also has found that teachers rate response cost and token economy procedures as acceptable, but prefer the response cost program (Anhalt, McNeil, \& Bahl, 1998; McGoey \& DuPaul, 2000; Reynolds \& Kelley, 1997). Furthermore, Filcheck (2003) found that teachers reported satisfaction with the Level System, but chose not to implement this program at follow-up. On the other hand, Filcheck, Greco, and McNeil found that the teacher chose to implement the Level System, though she reported low satisfaction with this program.

The teacher in the current study was interviewed and reported both advantages and disadvantages of the two programs. When asked to compare the two programs, she felt that the response cost had a stronger impact than the Level System on the children in the classroom because the children had fewer chances to engage in inappropriate behavior and still earn the reward. On the other hand, the teacher reported that the response cost program was a more negative program than the Level System, as the response cost did not allow the shapes to be moved back up the board. The moving of shapes up the board was a reported advantage of the Level System, but the frequent moving of shapes was time consuming. Furthermore, McGoey and DuPaul (2000) suggested that teachers may choose not to implement token economies because these systems require much time and effort from the teacher. The teacher in the current study further indicated that she was unsure as to whether the children attended to the frequent moving of shapes on the board. In addition, she felt the Level System may not be effective because the children are provided many chances for their shapes to move up the board and earn the reward. Thus, moving shapes down may not be punishing enough to lead to behavior change. When asked about modifications that could improve the programs, the teacher discussed the possibility of using the program on during challenging time periods and with a small group of 
children of the same age. McGoey and DuPaul also suggested that token economies may be difficult to implement in large classrooms.

Consistent with the study's hypotheses the parents preferred the Level System as indicated on the IRP, parent interview, and verbal report of choice of program. Parents indicated that they liked the Level System because this program targets and reinforces positive behaviors in children. Similarly, previous research found that parents of children with disruptive behavior report greater satisfaction with treatments focusing on positive behaviors than treatments that focus on negative behaviors (Jones, Eyberg, Adams, \& Boggs, 1998). An additional advantage of the Level System provided by the parents was that this program allows for children's shapes to be moved up the board possibly increasing their chances of earning rewards. The response cost program only allows the downward movement of shapes.

Child satisfaction also was assessed in the current study. Contrary to the hypotheses about child satisfaction, children preferred the response cost program to the Level System. The children may have chosen the response cost due to the position of the shapes. More specifically, shapes are placed at the top of the board in the response cost program and in the middle of the board for the Level System at the beginning of each time interval. The top-most level has a large sunshine picture while the middle level of the Level System contains no picture. In addition, the top of the board is associated with receiving a reward in both programs. Therefore, it is possible that the shape beginning at the top of the response cost board with the sunshine picture is associated with earning a reward while the middle level of the Level System is not associated with rewards. In addition, the length of the project may have contributed to the children's difficulty in remembering the response cost program. The response cost program was utilized approximately nine months prior to the children reporting program preference. Therefore, it may 
have been difficult for the children to remember enough about the programs and their differences to report a valid preference. The validity of child self-report also must be taken into consideration. The average age of the children interviewed in the current study was four years. Research has found that young children inaccurately report psychological symptoms. More specifically, a low correlation between child self-report and direct observation of psychological state was found in the literature (Finch \& Rogers, 1984). These four-year-old children also developmentally may have been incapable of completing the seriation required for the sunny face rating scale. Shields et al. (2003) found that only $42 \%$ of children in kindergarten were able to complete a seriation task, while Erickson (1990) suggested that children ages seven and older do not possess the cognitive capabilities to successfully engage in seriation. Therefore, child report of satisfaction with the treatment programs utilized in the current study may be an invalid measure of program preference.

Teacher skill also was examined in the current study. As expected the teacher used the most labeled praise statements during the Level System. This finding is consistent with previous research that also found increased use of teacher labeled praise during implementation of the Level System (Filcheck, Greco, Bernard, \& McNeil, 2003). The teacher was instructed to use these statements during the Level System phase, but not in other phases. Instructing the teacher to attend to appropriate behaviors and provide social rewards for those behaviors (i.e., verbal praise) could promote a more positive atmosphere in the classroom with the use of the Level System (Filcheck, Greco, Bernard, \& McNeil). Specifically, percent of intervals of appropriate child behaviors should increase as those behaviors are receiving reinforcement from the teacher. In addition, the teacher praised more at follow-up than at baseline. Filcheck (2003) also found this increase in teachers' use of labeled praises. The Level System may have impacted the 
teacher's skill by encouraging her to attend to and reinforce appropriate classroom behavior. The labeled praise statements may have resulted in improvements in classroom behavior, thus decreasing the necessity of the time-intensive Level System in managing behavior.

Unlabeled praises and criticisms also were examined to assess teacher skill. The teacher used more unlabeled praise statements toward the end of the study as compared to the beginning of the study. This finding may be attributed to the targeting of praise statements during the Level System condition. The teacher was instructed to use labeled praises during the Level System, but may have reverted to using unlabeled praise statements following the Level System condition. In other words, using praise may have become part of the teacher's behavioral repertoire. Without feedback, she, however, used vague, shorter unlabeled praise statements as opposed to the more difficult skill of specific labeled praise. The use of more unlabeled praises throughout the study also could be attributed to the children's behavior. More specifically, the teacher may have begun praising more as the children's appropriate behaviors improved. Unfortunately, the study's methodology does not permit conclusions to be made as to whether the teacher's use of praise influenced child behavior or child behavior influenced the teacher's use of praise. The teacher's use of criticisms continued to decrease as the study progressed. The frequency of criticisms may have been impacted by the students' behaviors. The decreasing trend in child inappropriate behaviors throughout the study may have resulted in fewer opportunities for the teacher to use critical statements. In addition, the teacher delivered a reduced amount of criticisms in the Level System as compared with the baseline, response cost, and withdrawal phases levels. The low percentage of intervals of criticisms during this phase would be expected as criticisms were targeted in the Level System condition. Further, the teacher was using more labeled and unlabeled praise statements thus decreasing the amount of time she would have to 
deliver critical statements.

\section{Limitations}

Participant selection. Child participants were selected for participation from teacher report of disruptive behavior on the CGI. There, however, were inconsistencies between teacher report and direct observations of child behavior. More specifically, the children identified by teacher report as exhibiting the most disruptive behavior in the classroom were not observed as exhibiting high rates of disruptive behavior. Percent of intervals of inappropriate behavior continued to decrease throughout the study for all children. A floor effect for inappropriate behavior occurred creating difficulty in distinguishing between treatment and no-treatment conditions based on these data. Further change in the dependent variable is difficult to detect when data reach a low limit (Kazdin, 1980). Therefore, the decrease in inappropriate behavior during the utilization of the response cost and withdrawal phases prohibit additional decrease in inappropriate behavior to occur throughout the study. In addition, the CGI may not have assessed the child behaviors with which the teacher was experiencing difficulty. Perhaps a different measure of child behavior or an interview with the teacher to identify target behaviors would improve the consistency between teacher report and direct observations of child data.

Observation Assessment. The observation system utilized for the current study provided 14 minutes of data per observation for each child participant. Thus a limited amount of behavioral data was obtained for each participant. Therefore, conclusions about the children's behavior are difficult to ascertain from 14 minutes of behavioral data. In addition, this short observation period may have contributed to the difficulty in establishing stability in child data. The teacher could have indicated the most difficult periods of the day. Observations could be conducted at those times to capture child inappropriate behavior. 
Study Confounds. The lack of reversal in child behavior to baseline levels with the removal of the interventions (i.e., during withdrawal conditions) was another limitation. This lack of reversal disallows conclusions to be made about the efficacy of the treatments in decreasing child disruptive behavior. Therefore, one or more variables may have been present that confounded the current data. These confounding variables may have included lengthy conditions, extended break from data collection, decrease in class size, and other interventions. Several study conditions were extended due to the difficulty in obtaining stability in the data. In addition, summer break from school created a long time interval between the response cost and first withdrawal phases. These two facets caused the project to extend for a longer period of time (i.e., approximately one year) than originally anticipated, and therefore may have lead to unexpected confounds and further limitations of this study (e.g., child maturation). Children were engaging in different activities throughout these conditions. For example, children were participating in outdoor activities in the summer and indoor activities in the winter and on rainy days. Thus, these different activities in different seasons may have impacted child classroom behavior. The number of students enrolled in this Head Start classroom decreased throughout the study. Initially there were approximately 18 children enrolled in the class. Following summer break, however, the number of students decreased to approximately 10 children due to the discontinuation of bus service. This decrease in the number of children could have lead to less teacher stress thus increasing her ability to utilize effective behavior management strategies. In addition, the teacher may have had more time to provide individual attention and social reinforcement to the children thus rewarding appropriate behavior. Finally, Ruby began taking stimulant medication during the Level System phase. Therefore, it is impossible to conclude whether a decrease in inappropriate behavior for Ruby was due to the interventions or the 
medication.

Limitations exist concerning the evaluation of satisfaction with and preference for the treatment programs. The teacher's dissatisfaction with the treatment programs may have impacted negatively on the implementation of the interventions. For example, it is possible that the teacher did not use the programs in their entirety when the research assistants were absent from the classroom, despite instructions to implement the programs all day. Unfortunately, treatment integrity only was assessed during those limited hours when research assistants were observing in the class. Thus, the potential impact of teacher satisfaction on the overall efficacy of the interventions cannot be determined. It is possible that teachers with children who have more severe behavior problems may be more receptive to treatment programs such as the response cost and Level System.

Assessment of child satisfaction involved showing the board for and reading a script concerning the two treatment programs (i.e., response cost and Level System). The children's preference for the response cost, however, could be attributed to several confounding variables. The wording of the scripts may not have been developmentally appropriate for the age of the children as the children's average age was four years. Although children's sustained attention increases and distractibility decreases with age, preschool children continue to have difficulty with these two tasks. More specifically, young children's attention quickly shifts from one stimulus to another. Preschool children typically move from one free-play activity to another within minutes (Dempster \& Corkill, 1999; Ruff \& Lawson, 1990). Therefore, the children in the current study developmentally may have been unable to attend to the scripts to allow understanding of the programs. The children also may have been distracted by classroom activities. While the children with parental consent were being interviewed, the other children in 
the classroom were preparing to exchange Valentine's Day cards. Therefore, this activity could have distracted the children's attention away from the scripts being read. An alternative technique to examine child preference could be having the children choose the program to implement for the day. The program chosen more often would suggest the preference or higher satisfaction than the program chosen least often.

This study also has limitations concerning the population and location. This study was conducted in one classroom with one teacher and three children. Therefore, the small sample size makes it difficult to generalize findings to the general population. Results of this study could be due to dynamics of this particular classroom that may not be representative of most Head Start classrooms. For example, the Head Start classroom in this study was located in rural Pennsylvania, and results may not be generalizable to urban Head Start classroom. Finally, the participants were exhibiting disruptive behaviors at low rates, and different results may be obtained in classrooms with children exhibiting more severe behavior problems.

\section{Directions for Future Research}

Future research should be conducted to determine the efficacy and social validity of these two programs (i.e., response cost and Level System), as well as their impact on teacher skill. These studies should examine the programs in both rural and urban Head Start classrooms to determine if the efficacies of these programs vary based on location. In addition, future research should be conducted utilizing a larger sample size to increase the ability of results to be generalizable to and representative of the larger population. Data collection should extend over a short period of time to ensure that young children will remember and be able to distinguish between the two programs and control for maturation effects. Individual data collection points, however, should be conducted for longer than 14 minutes per child to allow a more 
representative sample of each child's behavior. Furthermore, future research should utilize baseline observation data in addition to teacher report in determining child participants. Thus, floor effects in disruptive behavior could be avoided as children observed to be exhibiting high rates of disruptive behaviors would be chosen for participation.

Future research could examine the efficacy of teacher labeled praise compared to the Level System. This research design may allow one to determine if improvement in classroom behavior can be attributed to the entire Level System program or small components of that program. For example, decreased inappropriate classroom behavior may be obtained only with the use of teacher labeled praise. Future research also should be conducted to determine if these response cost and Level System programs impact child behavior. If child inappropriate behavior is found to decrease with these programs, perhaps the response cost and token economy programs could be used as a short-term training tool in schools and faded out of the classroom following behavior change. Short-term implementation of the program may teach skills to both teachers and students that can be maintained following termination of the program. Future research, however, will be necessary to conclude whether the response cost and token economy programs can make an impact on behavior problems in preschool classrooms. 


\section{References}

Anhalt, K., McNeil, C. B., \& Bahl, A. B. (1998). The ADHD Classroom Kit: A whole-classroom approach for managing disruptive behavior. Psychology in the Schools, 35, 67-79.

Bahl, A. B., McNeil, C.B., Cleavenger, C. J., Blanc, H. M., \& Bennett, G. M. (2000). Evaluation of a whole-classroom approach for the management of disruptive behavior. Proven Practice, 2, 62-71.

Baker, J. G., Stanish, B., \& Fraser, B. (1972). Comparative effects of a token economy in nursery school. Mental Retardation, 10(4), 16-19.

Barkley, R. A. (1997). Defiant children: A clinician's manual for assessment and parent training. ( $2^{\text {nd }}$ ed.). New York: Guilford.

Beare, P. L., \& Lynch, E. C. (1986). Under identification of preschool children at risk for behavioral disorders. Behavioral Disorders, 11, 177-183.

Boivin, M., Hymel, S., \& Burkowski, W. M. (1995). The roles of social withdrawal, peer rejection, and victimization by peers in predicting loneliness and depressed mood. Development and Psychopathology, 7(4), 765-785.

Brandenberg, N. A., Friedman, R. M., \& Silver, S. (1987). The epidemiology of childhood psychiatric disorders: Recent prevalence findings and methodological issues. Tampa: Florida Mental Health Institute, University of South Florida.

Buscemi, L. Bennett, T., Thomas, D., \& DeLuca, D. A. (1995). Head Start: Challenges and training needs. Journal of Early Intervention, 20(1), 1-13.

Campbell, S. (1990). Behavior problems in preschool children. New York: Guilford.

Campbell, S. (1995). Behavior problems in preschool children: A review of recent research. Journal of Child Psychology and Psychiatry, 36(1), 113-149. 
Campbell, S. B., \& Ewing, L. (1990). Hard-to-manage preschoolers: Adjustment at age nine and predictors of continuing symptoms. Journal of Child Psychology and Psychiatry, 26, 871889.

Conners, C. K. (1969). A teacher rating scale for use in drug studies with children. American Journal of Psychiatry, 126, 884-888.

Conners, C. K. (1997). Conners’ Rating Scales - Revised. New York: Multi-Health Systems Inc.

Dempster, F. N., \& Corkill, A. J. (1999). Interference and inhibition in cognition and behavior: Unifying themes for educational psychology. Educational Psychology Review, 11, 1-88.

DeRosier, M. E., Cillessen, A. H. N., Coie, J. D., \& Dodge, K. A. (1994). Group social context and children's aggressive behavior. Child Development, 65(4), 1068-1079.

Epstein, M. H., \& Nieminen, G. S. (1983). Reliability of the Conners' Abbreviated Teacher Rating Scale across raters and across time: Use with learning disabled students. School Psychology Review, 12, 337-339.

Erickson, C. J. (1990). Pain management in children: Problems and directions. Journal of Developmental and Behavioral Pediatrics, 11, 135-137.

Eyberg, S. M., Bessmer, J., Newcomb, K., Edwards, D., \& Robinson, E. (1994). Dyadic ParentChild Interaction Coding System II: A Manual. Social and Behavioral Sciences Documents. (Ms. No. 2897).

Filcheck, H. A. (2003). Evaluation of a whole-class token economy to manage disruptive behavior in a preschool classroom. Unpublished doctoral dissertation. West Virginia University.

Filcheck, H. A., Greco, L. A., Bernard, R. S., \& McNeil, C. B. (in press). Using a whole-class token economy and PCIT skills in a preschool classroom to manage disruptive behavior. 
Psychology in the Schools.

Finch, A. J., \& Rogers, T. R. (1984). Self-report instruments. In T. H. Ollendick \& M. Hersen (Eds.), Child behavioral assessment: Principles and procedures (pp. 106-123). New York: Pergamon Press.

Fischer, M., Rolf, J. E., Hasazi, J. E., Cummings, L. (1984). Follow-up of a preschool epidemiological sample: Cross-age continuities and predictions of later adjustment with internalizing and externalizing dimensions of behavior. Child Development, 55, 137-150.

Forness, S., Serna, L., Kavale, K., \& Nielsen, E. (1998). Mental health and Head Start: Teaching adaptive skills. Education and Treatment of Children, 21, 258-274.

French, D. C., Conrad, J. \& Turner, T. M. (1995). Adjustment of antisocial and nonantisocial rejected adolescents. Development and Psychopathology, 7(4), 857-874.

Goldstein, A. P., Harootunian, B., \& Conoley, J. C. (1994). Student Aggression: Prevention, management, and replacement training. New York: Guilford.

Greene, L., Kamps, D., Wyble, J., \& Ellis, C. (1999). Home-based consultation for parents of young children with behavioral problems. Child and Family Behavior Therapy, 32(2), 1945.

Handen, B. L., Parrish, J. M., McClung, T. J., Kerwin, M. E., \& Evans, L. D. (1992). Using guided compliance versus time out to promote child compliance: A preliminary comparative analysis in an analogue context. Research in Developmental Disabilities, 13, $157-170$.

Harden, B. J., Winslow, M. B., Kendziora, K. T., Shahinfar, A., Rubin, K. H., Fox, N. A., et al. (2000). Externalizing problems in Head Start children: An ecological exploration. Early Education and Development, 11(3), 357-385. 
Hembree-Kigin, T. T., \& McNeil, C. B. (1995). Parent-Child Interaction Therapy. New York: Plenum Press.

Horner, R. H., Dunlap, G., Koegel, R. L., Carr, E. G., Sailor, W., Anderson, J., Albin, R. W., \& O’Neill, R. E. (1990). Toward a technology of "nonaversive" behavioral support. Journal of The Association for Persons with Severe Handicaps, 15(3), 125-132.

Iwata, B. A., \& Bailey, J. S. (1974). Reward versus cost token systems: An analysis of the effects on students and teachers. Journal of Applied Behavior Analysis, 7(4), 567-576.

Jacobs, J. R., Boggs, S. R., Eyberg, S. M., Edwards, P. D., Querido, J. G., McNeil, C. B., \& Funderburk, B. W. (2000). Psychometric properties and reference point data for the revised edition of the School Observation Coding System. Behavior Therapy, 31, 695-712.

Jones, M. L., Eyberg, S. M., Adams, C. D., \& Boggs, S. R. (1998). Treatment acceptability of behavioral interventions for children: An assessment by mothers of children with disruptive behavior disorders. Child and Family Behavior Therapy, 20, 15-26.

Jones, R. M., Sloane, H. N., \& Roberts, M. W. (1992). Limitations of "Don't" instructional control. Behavior Therapy, 23, 131-140.

Kaiser, A. P., Hancock, T. B., Cai, X., Foster, E. M., \& Hester, P. P. (2000). Parent-reported behavioral problems and language delays in boys and girls enrolled in Head Start classrooms. Behavioral Disorders, 26(1), 26-41.

Kassebaum, N. L. (1994). Head Start: Only the best for America's children. American Psychologist, 49(2), 123-126.

Kazdin, A. E. (1980). Research design in clinical psychology. New York: Harper \& Row.

Keenan, K., \& Wakschlag, L. S. (2000). More than the terrible twos: The nature and severity of behavior problems in clinic-referred preschool children. Journal of Abnormal Child 
Psychology, 28(1), 33-46.

Kraatz-Keiley, M., Bates, J. E., Dodge, K. A., \& Pettit, G. S. (2000). A cross-domain growth analysis: Externalizing and internalizing behavior problems during 8 years of childhood. Journal of Abnormal Child Psychology, 28(2), 161-179.

Kupersmidt, J. B., Bryant, D., \& Willoughby, M. T. (2000). Prevalence of aggressive behaviors among preschoolers in Head Start and community child care programs. Behavioral Disorders, 26(1), 42-52.

Lahey, B. B., McNees, M. P., \& McNees, M. C. (1973). Control of an obscene "verbal tic" through timeout in an elementary school classroom. Journal of Applied Behavior Analysis, 6(1), 101-104.

Laird, R. D., Jordan, K. Y., Dodge, K. A., Pettit, G. S., \& Bates, J. E. (2001). Peer rejection in childhood, involvement with antisocial peers in adolescence, and the development of externalizing behavior problems. Development and Psychopathology, 13(2), 337-354.

Lara, S. L., McCabe, L. A., \& Brooks-Gunn, J. (2000). From horizontal to vertical management styles: A qualitative look at Head Start staff strategies for addressing behavior problems. Early Education and Development, 11(3), 283-306.

Loeber, R. (1990). Development and risk factors of juvenile antisocial behavior and delinquency. Clinical Psychology Review, 10, 1-41.

Margalit, M. (1983). Diagnostic application of the Conners' Abbreviates Symptom Questionnaire. Journal of Clinical Child Psychology, 12, 355-357.

McGee, R., Silva, P. A., \& Williams, S. (1984). Perinatal, neurological, environmental, and developmental characteristics of seven-year-old children with stable behavior problems. Journal of Child Psychology and Psychiatry, 25, 573-586. 
McGoey, K. E., \& DuPaul, G. J. (2000). Token reinforcement and response cost procedures: Reading the disruptive behavior of preschool children with Attention-Deficit/Hyperactivity Disorder. School Psychology Quarterly, 15, 330-343.

McLoyd, V. C. (1990). The impact of hardship on Black families and children: Psychological distress, parenting, and socioemotional development. Child Development, 61, 311-346.

McNamara, J. R. (1971). Teachers and students as a source for behavior modification in the classroom. Behavior Therapy, 2, 205-213.

McNeil, C. B. (2000). The Tough Class Discipline Kit. Longmont, CO: Sopris West.

McNeil, C. B., Clemens-Mowrer, L., Gurwitch, R. H., \& Funderburk, B. W. (1994). Assessment of a new procedure to prevent timeout escape in preschoolers. Child and Family Behavior Therapy, 16(3), 27-35.

McNeil, C. B., Eyberg, S., Eisenstadt, T H., Newcomb, K., \& Funderburk, B. (1991). ParentChild Interaction Therapy with behavior problem children: Generalization of treatment effects in the school setting. Journal of Clinical Child Psychology, 20, 140-151.

McNeil, C. B., \& Filcheck, H. A. (2001). The Level System manual. Unpublished manuscript.

Merrett, F., \& Wheldall, K. (1993). How do teachers learn to manage classroom behaviour? A study of teachers' opinions about their initial training with special reference to classroom behaviour management. Educational Studies, 19(1), 91-106.

Molina, B. S. G., Pelham, W. E., Blumenthal, J., \& Galiszewski, E. (1998). Agreement among teachers' behavior ratings of adolescents with a childhood history of attention deficit hyperactivity disorder. Journal of Clinical Child Psychology, 27, 330-339.

O’Leary, K. D., \& Becker, W. C. (1967). Behavior modification of an adjustment class: A token reinforcement program. Exceptional Children, 33, 637-642. 
Parsonson, B. S., \& Baer, D. M. (1992). The visual analysis of data, and current research into the stimuli controlling it. In T. R. Kratochwill \& T. R. Levin (Eds.), Single-case research design and analysis: New directions for psychology and education (pp. 106123). Hillsdale, NJ: Erlbaum.

Peter D. Hart Research Associates. (1995). Key findings from a nationwide survey of AFT teaching members. Washington, DC: Author.

Pettit, G. S., Clawson, M. A., Dodge, K. A., \& Bates, J. E. (1996). Stability and change in peerrejected status: The role of child behavior, parenting, and family ecology. Merrill Palmer Quarterly, 42(2), 267-294.

Piotrkowski, C. S., Collins, R. C., Knitzer, J., \& Robinson, R. (1994). Strengthening mental health services in Head Start. American Psychologist, 49, 133-139.

Reynolds, L. K., \& Kelley, M. L. (1997). The efficacy of a response cost-based treatment package for managing aggressive behavior in preschoolers. Behavior Modification, 21(2), 216-230.

Rubin, K. H., \& Mills, R. S., L. (1988). The many faces of social isolation in childhood. Journal of Consulting and Clinical Psychology, 56, 916-924.

Ruff, H. A., \& Lawson, K. R. (1990). Development of sustained, focused attention in young children during free play. Developmental Psychology, 26, 85-93.

Sarafino, E. P. (2001). Behavior modification: Understanding principles of behavior change. $\left(2^{\text {nd }}\right.$ ed.). Mountain View, CA: Mayfield Publishing Co.

Schloss, P. J., \& Smith, M. A. (1994). Applied behavior analysis in the classroom. Boston: Allyn and Bacon.

Schonfeld, I. S., Shaffer, D., O’Connor, P., \& Portnoy, S. (1988). Conduct disorder and cognitive 
functioning: Testing three causal hypotheses. Child Development, 59, 993-1007.

Shields, B. J., Palermo, T. M., Powers, J. D., Grewe, S. D., \& Smith, G. A. (2003). Predictors of a child's ability to use a visual analogue scale. Child: Care, Health \& Development, 29, 281-290.

Stage, S, \& Quiroz, D. (1997). A meta-analysis of interventions to decrease disruptive classroom behavior in public education settings. School Psychology Review, 26, 333-368.

Stormshak, E. A., Bierman, K. L., Bruschi, C., Dodge, K. A., \& Coie, J. D. (1999). The relation between behavior problems and peer preference in different classroom contexts. Child Development, 70(1), 169-182.

Sturge, C. (1982). Reading retardation and antisocial behavior. Journal of Child Psychology and Psychiatry, 23, 21-31.

Sullivan, M. A., \& O’Leary, S. G. (1990). Maintenance following reward and cost token programs. Behavior Therapy, 21, 139-149.

Swiezy, N. B., Matson, J. L., \& Box, P. (1992). The Good Behavior Game: A token reinforcement system for preschoolers. Child and Family Behavior Therapy, 14(3), 21-32.

Taylor, A. R. (1989). Predictors of peer rejection in early elementary grades: Roles of problem behavior, academic achievement, and teacher preference. Journal of Clinical Child Psychology, 18(4), 360-365.

U.S. Department of Health and Human Resources (2001). Head Start FACES: Longitudinal findings and program performance. Washington DC: Author.

Webster-Stratton, C. (1990). Stress: A potential disruptor of parent perceptions and family interactions. Journal of Clinical Child Psychology, 19, 302-312.

Witt, J. C., Elliott, S. N., \& Martens, B. K. (1984). Acceptability of behavioral interventions used 
in the classroom: The influence of amount of teacher time, severity of behavior problems, and type of intervention. Behavioral Disorders, 9, 95-104.

Witt, J. C., \& Martens, B. K. (1983). Assessing the acceptability of behavioral interventions used in classrooms. Psychology in the Schools, 20, 510-517.

Wolfe, V. V., Boyd, L. A., \& Wolfe, D. A. (1983). Teaching cooperative play to behaviorproblem preschool children. Education and Treatment of Children, 6(1), 1-9.

Wolf, M. M., Hanley, E. L., King, L. A., Lachowicz, J., \& Giles, D. K. (1970). The timer-game: A variable interval contingency for the management of out-of-seat behavior. Exceptional Children, 37, 113-117.

Zabel, M. K. (1986). Time-out use with behaviorally disordered students. Behavioral Disorders, $12,15-21$. 


\section{Appendix A}

\section{The Level System Manual}

The Level System will be used as a way to provide immediate positive attention to appropriate behavior and give an immediate warning and a minor consequence for inappropriate behavior.

To implement Level System for the whole class.

- Each child is assigned a certain shape on the System.

- The Level System should be posted somewhere in the room so that the children are able to see where his or her shape is on the System. It should remain visible during the entire class period.

- Children move up for appropriate behavior (e.g., sitting correctly, putting coat in the cubby, following class rules) and down for inappropriate behavior (i.e., annoying and obnoxious behavior, not following class rules).

- When children move up, they are given a labeled praise (i.e., specific praise such as "Thank you for sitting in your seat") for the appropriate behavior.

- Children first are given a warning for inappropriate behavior, and then if they do not begin to behave appropriately, they move down. For example, the teacher would say, "You have two choices. You can either put the crayons in the basket, or you will move down into the cloudy area." Alternatively, the teacher can use a visual two-choice warning without words and simply say the child's name. Then if the child did not begin to behave appropriately, the teacher would move the child down.

- Children are not given a warning for hurting others (e.g., hitting other children and making them cry) or destruction of property (e.g., tearing up other children's work); they simply are moved down a level. The teacher has the option of adding a consequence (e.g., time out) when the child is moved down for these behaviors.

- If a child continues to misbehave after being moved down a level, give the child another warning if appropriate (i.e., not huring or destruction), and if he or she still continues to misbehave, move the child shape down a level again. If the misbehavior continues after you have moved the child's shape down 2 times, provide another consequence, such as time-out, that you would typically give to that child who engaged in that misbehavior.

- At the end of periods of approximately 40 minutes, the teacher should give out the rewards. All children in the sunny area of the Level System receive a reward (e.g., sticker, activity), but if the child in the cloudy area, the child does not receive the reward, and all children in the cloudy area do not receive the reward. 
- The rewards are printed on the cards, and all of the children receive the same reward. The teacher should give out the rewards at least once during a 40-minute time period.

- Each reward card should be used once before any reward card is used again. Place the used reward cards in the envelope so that the teacher knows which cards have been used.

- After the reward is given to the children, all of the children's shapes are placed back in the neutral area, and a new period begins where they can earn a reward. The children essentially are starting over for the next period.

- All of the children in the class should have equal access to the rewards. To ensure that the children are receiving the rewards with the same frequency:

o Expectations must be individualized for each child, so that some children will move up for simply not hurting another child for a few minutes, or for staying seated for a few seconds. These expectations should be increased when the child masters them.

o The teacher must complete the Daily Reward Log to monitor which children receive a reward or not. If some children continually are not receiving the reward, then that child's expectations must be lowered so that he or she may have access to the reward.

- The Level System should be used for all transitions (e.g., moving from circle time to structured activity, play time to clean-up). In other words, the teacher should move all of the names (either up or down) following every transition.

\section{What if the child is in the $3^{\text {rd }}$ cloudy level?}

If a child is in the $3^{\text {rd }}$ cloudy level of the system, take the child aside and discuss the rules with that child. In addition, the teacher should lower his or her expectations for that child and focus on small positive behaviors so that the child will receive positive feedback and be able to move up the Level System. For example, if a child is behaving aggressively, the teacher can tell the child that if he or she can play gently, the shape will be moved up a level. Another example would be to start the child back in the neutral zone.

\section{What if the child is in the $3^{\text {rd }}$ sunny level?}

If a child is in the $3^{\text {rd }}$ sunny level of the system, the child should still receive a labeled praise for behaving appropriately even though he or she cannot move up any more.

\section{Correct Use of the Level System}

1. Moving the child's shape up a level for appropriate behavior.

2. Providing a warning for inappropriate behavior.

3. Providing a warning, and then moving the child's shape down when the inappropriate behavior continues.

4. Providing a warning, then moving the child's shape down, then providing a warning again, then moving the child's shape down again when the inappropriate behavior 
continues.

5. Providing a warning, then moving the child's shape down, then providing a warning again, then moving the child's shape down again, then providing a back up consequence (e.g., time-out) when the inappropriate behavior continues.

\section{Common Problems with the Level System}

1. No warning is given for inappropriate behavior (not hurting or destruction of property), the child's shape is simply moved down.

2. Providing a warning in a critical manner.

3. Forgetting to label praise the child's behavior when the child's shape is moved up.

4. Providing a warning, but forgetting to move the child's shape down when the behavior continues.

5. Using criticism or nagging instead of providing a warning for misbehavior.

6. Providing a warning for hurting or destruction of property.

7. Not praising a child's behavior or moving them up for appropriate behavior.

8. Providing more than 1 warning before moving the child's shape down.

9. Not providing a warning or moving a child's shape down for inappropriate behavior. 


\section{Appendix B}

\section{Rewards}

\section{\#1 STICKER}

\section{\#2 TREAT}

\section{\#3 HAND STAMP}

\section{\#4 CHARADES}

Rules: Up to three children will simultaneously act out one of these charades while the other players try to guess. No words are allowed.

- Digging

- Cutting with scissors

- Sleeping

- Laughing

- Eating corn on the cob

- Kicking a ball

- Monster

- Dancing

- Cooking

- Skating

- Taking a bath

- Flying a kite

- Falling down

- Waking up
- Frog

- Monkey

- Shooting a bow and arrow

- Fighting

- Swimming

- Sneezing

- Cat

- Playing the piano

- Skipping

- Blowing bubbles

- Stretching

- Playing the drums

- Driving a car

- Reading a book
- Standing on your head

- Opening a door

- Brushing your hair

- Juggling

- Flying

- Standing up

- Standing on your tip toes

- Jumping

- Playing soccer

- Catching a ball

- Holding your breath

- Throwing a snowball

- Playing cards

- Playing baseball

\section{\#5 ACTIVITY}

Rules: Teacher chooses one of the following:

- Act like a tightrope walker in the circus.

- Get a partner and pretend like you are taking a dog for a walk; one player will be the owner and the other will be the dog. Then switch.

- Act like a monkey eating a banana.

- $\quad$ Players stand in lines with legs apart. Children take turns being a snake and crawling through the tunnel.

- Choose a partner. Pretend like you are a dog fetching a stick. One player pretends to be the dog's owner. The other pretends to be the dog. Then switch.

- Act like you are building a sand castle at the beach.

- Act like your favorite zoo animal.

- Walk across the room holding your ankles.

- Close your eyes. Try to describe the clothes that the child next to you is wearing.

- Pretend to be a juggling clown.

- Act like a baby who is just learning to walk.

- With a partner, try to hold hands and walk backwards across the room. 
- Pretend to be an airplane taking off.

- Act like a cheerleader at a football game.

- Do the bear walk. Walk with your hands and feet (but not your knees) on the floor.

- Act like an angry tiger.

- Walk across the room using baby steps (touching your heel to the tips of your toes).

- See how far you can walk with a piece of paper (or a book) on your head.

- Pretend to be the slowest turtle in the world.

- Wiggle your body all over while singing "Twinkle, Twinkle, Little Star."

\section{\#6 GUESS WHO'S MISSING}

Rules: Children sit randomly on the floor. Everyone will put their heads in their lap and close their eyes. The teacher will tap someone on the head and ask him or her to hide (e.g., behind the teacher's desk, in the hall). Children will try to figure out who is missing. They are to keep quiet until everyone has had a chance to think it over. Then they can guess out loud. (As a variation, teachers can choose two children to hide.)

\section{\#7 SIMON SAYS}

Rules: Children are to follow the leader's instructions only if the words "Simon Says" follow the instruction. Either the teacher or a chosen student can be the leader. If a child engages in the instruction without the "Simon Says" preface, the child must sit out. Examples of "Simon Says" instructions include: "put your hands on your knees," "touch your nose," "turn around in a circle," "shake your neighbor's hand," and "give yourself a hug."

\section{\#8 PROHIBITED MOVEMENTS}

Rules: The children form a circle. They stand at the distance of stretched arms from each other. The teacher chooses a leader to be in the center of the circle. He/she makes different movements and the other children repeat all of them exactly. But there are 2 movements that the children mustn't repeat. Instead of them they must make other movements. The teacher tells the children what these movements are at the beginning of the game (e.g., jumping, clapping hands, bending knees). The children who make mistakes are out.

\section{\#9 LIMBO CONTEST}

Rules: Teacher holds out a pointer (ruler or stick). Children try to go under the pointer by leaning backwards. Children who touch the pointer or fall down are eliminated.

\section{\#10 HOT POTATO}

Rules: Have the players sit in a circle. Use a bean bag (teddy bear, book) as the "hot potato". Choose one child to sit with his or her back to the group. Once the children begin passing the "hot potato" around quickly, the child will shout, "HOT POTATO!". Whoever has the potato at that time will have to sit out.

\section{\#11 FOLLOW THE LEADER}

Rules: Teacher will choose a leader. All of the other players will line up behind the leader. The leader will be instructed to walk around and do funny things (like crawling, jumping, patting the desk, whistling). Sequentially (taking turns down the line), each person will follow the leader's activities. 


\section{\#12 BAG (BALL) TOSS}

Rules: Teacher cleans out a trash can (box or bag). Using a bean bag or ball, have each child try to throw the object into the can. The game can be varied by having the children stand further away or having them bounce the ball before it enters the can.

\section{\#13 OVER AND UNDER RELAY}

Rules: Have players line up in two lines. Using any object (block, stuffed animal, bean bag), have players hand the object to the person behind them. The first player hands it over their head. The second player accepts it up high but then passes it through the legs. The passing is alternated, over then under then over then under. When they get to the end of the line, they turn around and go back the other way. The first team to relay the object back to the line leader wins.

\section{\#14 "STOP THE MUSIC! I'M TIRED."}

Rules: Using music or hand clapping, have players walk around in a circle. When music or clapping stops, the children are to sit on their bottoms as quickly as possible. The last child to sit on his or her bottom must sit out. Then the music/clapping begins again. (If chairs are used, this game is called "musical chairs".) Children can be fooled by changing the volume or pace. If a child sits before the music/clapping stops, (s)he must sit out.

\section{\#15 PASS A HAT}

Rules: The children are in a circles. One child has a hat on his/her head. The object is to pass the hat round the circle. But the children mustn't use their hands while passing the hat from head to head.

\section{\#16 HOT POTATO/NAME TOSS}

Rules: Choose a "hot potato" caller. Then, have the rest of the children stand in two lines that face each other. Using a bean bag, ball, or stuffed animal as the "hot potato", have children throw the "hot potato" to each other as quickly as possible. The trick is that they have to say the person's name (can also use last names and initials) before throwing the "hot potato." Whoever is holding the hot potato when the caller yells "HOT POTATO!" has to sit out.

\section{\#17 DUCK, DUCK, GOOSE}

Rules: Teacher chooses one person to be "it" and walk around the circle. As they walk around, they tap people's heads and say whether they are a "duck" or a "goose". Once someone is the "goose" they get up and try to chase "it" around the circle. The goal is to tap that person before they are able sit down in the "goose's" spot. If the goose is not able to do this, they become "it" for the next round and play continues. If they do tap the "it" person, the person tagged has to sit in the center of the circle. Then the goose becomes it for the next round. The person in the middle can't leave until another person is tagged and they are replaced.

\section{\#18 RED LIGHT, GREEN LIGHT}

Rules: All the kids line up away from the teacher. When the teacher says green light, all the kids run, walk, crawl, hop (teacher's decision) as fast as they can. When the teacher says red light, everyone stops. Whoever doesn't stop is out. The teacher keeps saying red light or green light until all the kids are out or has gone from one end of the room to the other. 


\section{\#19 WHO HAS A TOY?}

Rules: The teacher puts toys on the floor and has the children form a circle around the toys. The teacher then plays music. As the music plays everyone walks around the circle. When the music stops everyone must grasp a toy. A person who doesn't have a toy is out. The number of toys should lessen every time.

\section{\#20 DOGGY, DOGGY, WHERE'S YOUR BONE?}

Rules: A student is chosen to be the "dog." The dog sits with his or her back to the class and eyes closed. An eraser or another object (bone) is put under the chair. The teacher chooses someone to sneak up and steal the bone and hide it somewhere on themselves. Then everyone sings: "Doggy, Doggy, where's your bone? Somebody's stole it from your home. Guess who it might be." Then the dog has three chances to guess who took it. If the dog guessed right then he got to do it again. If he guessed wrong than the person who had the bone got a turn as the dog.

\section{\#21 BUBBLE GUM}

Rules: Everyone sits in a tight circle and makes a fist with both hands and holds their fists out in the center of the circle. The teacher chooses a counter who takes one of his fists and taps everyone's fists (including his own) as he says this rhyme: "Bubble gum, Bubble gum, in a dish. How many pieces do you wish?" Who ever he taps last would give a number between 1 and 10 . Then the counter taps everyone's fists as he/she counts to the specified number. Who ever he landed on had to take that fist out of the circle and place their hand behind their back. This can continue until the time is up.

\section{\#22 TOSS THE BALL}

Rules: The children form a circle. The teacher chooses one person to start with the ball. He/she names a particular person in the group and throws the ball to him/her. That person must catch the ball then names another person of the group and also throws the ball to him/her.

\section{\#23 SAUSAGE}

Rules: Everyone sits in a circle. The person who the teacher chooses to be "it" stands in the center of the circle. Each person asks the person who is "it" an appropriate question. The only answer to every question can be sausage. The first person to make the center person laugh wins a try in the middle. Ex: What color is your hair? Sausage. What do you brush your teeth with? Sausage.

\section{\#24 BUTTON, BUTTON, WHO HAS THE BUTTON?}

Rules: The children all stand in a circle with one person in the middle. That person has a button between his hands that he is going to drop into one of the other player's hands. The object of the game is to go around the circle pretending to drop the button, but not letting the others know who has the button. Then the other players guess who has the button. Whoever finally guesses correctly gets to be in the middle and drop the button.

\section{\#25 WINDOWS AND DOORS}

Rules: The children form a circle holding hands. Then they spread out enough so that everyone's arms are straight out, to form large spaces between kids. These are the windows and doors. Then 
the teacher chooses one child to start running, and weaving in and out between children. The children in the circle randomly drop their arms down trying to touch or trap the person weaving their way in and out. Once the person is caught or touched by the arms of someone, they are out. The child that caught them is the next to weave in and out of the windows and doors.

\section{\#26 COWBOY SCHOOL}

Rules: The teacher says "Cowboy school has just begun. No more laughing, no more fun. If you show your teeth or tongue, you will have a penalty done." The teacher then precedes to do silly things to make the children laugh. The kids that laugh hard enough that their mouths opened, exposing teeth and/or tongues, have to do whatever the teacher tells them to do (run around the room, hop on one leg, do jumping jacks).

\section{\#27 SLEEPING LIONS}

Rules: All of the children (except one or two hunters) lie down on the floor in sleeping positions. Once they are settled, they are not allowed to move. The hunters walk through the room and try to make the sleeping lions move by making them laugh, and telling them jokes. The hunters are not allowed to touch the lions. Once the lions have moved, they get up and join the hunters.

\section{\#28 LION'S CUB}

Rules: The teacher selects a person to be the Lion. The lion sit with their back to the other children at least ten feet away. The teacher puts a stuffed animal behind the lion and has the lion pretend it is his cub. The other children take turns sneaking up behind the Lion and trying to steal the cub. If the lion hears the person sneaking up it can roar and then turn around. If the lion has caught a child, that child takes the lions place and the lion goes back to the other children.

\section{\#29 LAND, WATER}

Rules: The teacher says the words "land" and "water." On hearing the word "land" the children jump forward, on hearing the word "water" backward. When a child makes a mistake, her or she is out. 


\section{Appendix C}

\section{Conner's Global Index}

Child Rated:

Rater:

Date:

\section{Instructions}

Read each item below carefully, and decide how much you think your student has been bothered by this problem in the past month. For each behavior described below, circle one number to indicate how much of a problem the behavior was for your student.

\begin{tabular}{|l|c|c|c|c|}
\hline & Not at all & Just a little & $\begin{array}{l}\text { Pretty } \\
\text { Much }\end{array}$ & $\begin{array}{l}\text { Very } \\
\text { much }\end{array}$ \\
\hline 1. Restless in the "squirmy" sense & 0 & 1 & 2 & 3 \\
\hline $\begin{array}{l}\text { 2. Temper outbursts, unpredictable } \\
\text { behavior }\end{array}$ & 0 & 1 & 2 & 3 \\
\hline $\begin{array}{l}\text { 2. Distractibility or attention span a } \\
\text { Problem }\end{array}$ & 0 & 1 & 2 & 3 \\
\hline 4. Disturbs other children & 0 & 1 & 2 & 3 \\
\hline 5. Pouts and sulks & 0 & 1 & 2 & 3 \\
\hline 6. Mood changes quickly and drastically & 0 & 1 & 2 & 3 \\
\hline 7. Restless, always up and on the go & 0 & 1 & 2 & 3 \\
\hline 8. Excitable, impulsive & 0 & 1 & 2 & 3 \\
\hline 9. Fails to finish things & 0 & 1 & 2 & 3 \\
\hline 10. Easily frustrated in efforts & 0 & 1 & 2 & 3 \\
\hline
\end{tabular}




\section{Appendix D}

\section{Revised Edition of the School Observation Coding System \\ Definitions of Behavior}

\section{Category: Inappropriate Behavior}

A. Appropriate Behavior: The absence of inappropriate behavior for the entire 10 -second interval. If unsure as to whether the behavior was appropriate or inappropriate, code Appropriate Behavior.

B. Inappropriate Behavior: Behaviors are coded as Inappropriate Behaviors because they are annoying or disruptive to the target child, the teacher, or other children.

Definitions of Inappropriate Behaviors:

1. Whining - Coherent words uttered by the child in a slurring, nasal, high-pitched, voice.

2. Crying - Inarticulate utterances of distress (e.g., audible weeping) that may or may not be accompanied by tears.

3. Yelling - Loud screeching, screaming, shouting, or crying. The sound must be loud enough so that it is clearly above the intensity of normal indoor conversation. Not coded during outdoor recess observations.

4. Destructiveness - Behaviors during which the child damages or destroys an object or threatens to damage an object. Do not code destructiveness if it is appropriate within the context of play situation (e.g., ramming cars in a car crash).

5. Aggressive Behavior - Examples include fighting, kicking, slapping, hitting, grabbing an object roughly from another person, or threatening to do any of the preceding. 
6. Negativism - Verbal or nonverbal behavior expressing a negative attitude.

Negativism may be scored when the child makes a neutral comment that is delivered in a tone of voice that conveys an attitude of "don't bother me." Negativism may be expressed in a derogatory, uncomplimentary, or angry manner. Also included are defeatist statements such as "I give up", contradictions of another person, and teasing or mocking behaviors or verbalizations. "Pouting" facial expressions are included in this category.

7. Self-Stimulation - Repetitive physical movements (involving only the child's body and not other objects) that may be harmful and that interfere with a child's ability to attend or complete a task. Examples include head-banging, thumb-sucking, and masturbation.

8. Demanding Attention - Includes inappropriate verbal or nonverbal requests for attention from the teacher or other students (e.g., "Call on me! Call on me! Call on me!). Examples include tugging on the teacher's sleeve, tapping a neighbor on the shoulder, waving arms in the air, and passing notes to another child.

9. Disruptive Behavior - Any physically active or repetitive behavior that is or may become disruptive to others or interfere with the target child's ability to attend or complete a task. Examples include kicking a child's chair repeatedly, drumming on the table loudly, clowning, making funny noises, teasing, or spinning a pencil on the desk.

10. Talking Out of Order - Any talking when the class has been instructed to be silent unless called on to speak. This includes situations in which a "classroom rule" exists that silence is to be maintained (i.e., the teacher does not have to give the instruction 
explicitly - the expectation for silence is sufficient). Examples include whispering to a neighbor, answering a question directed to someone else, calling out to another child, and talking, singing, or humming to oneself.

11. Being Out of Area - Coded when the target child, without permission, leaves the area to which s/he is assigned. Examples include standing up when the rest of the class is seated, leaving the desk, approaching the teacher without permission, or playing with a toy that is not in the child's assigned work area the child is suppose to be. The behavior must be appropriate for the context or classroom norms (e.g., in some classrooms children are allowed walk to the teacher's desk to obtain help with an assignment).

12. Defiance-Coded when the target child does not comply with a command or direction. Examples include not picking up the toys when the class is told it is time to clean up, not coming to circle time, or standing out of line when the class lines up to go outside the classroom.

C. Not Applicable: Coded when there is no readily identifiable task that the child is expected to perform. Examples of Not Applicable activities include free play and unstructured recess time. 


\section{Appendix E \\ Definitions}

A. Labeled Praise: Labeled praise provides a positive evaluation of a specific behavior, activity, or product of the child.

B. Unlabeled Praise: Unlabeled praise provides a positive evaluation of the child, an attribute of the child, or a nonspecific activity, behavior, or product of the child.

C. Criticism: A verbal expression of disapproval for the child or the child's attributes, products, or choices. 
Appendix F

Behavioral Observation Coding Sheet

Coder:

Ruby:

Teacher:

Damon:

RUBY
Date:

Mitch:

DAMON
Time:

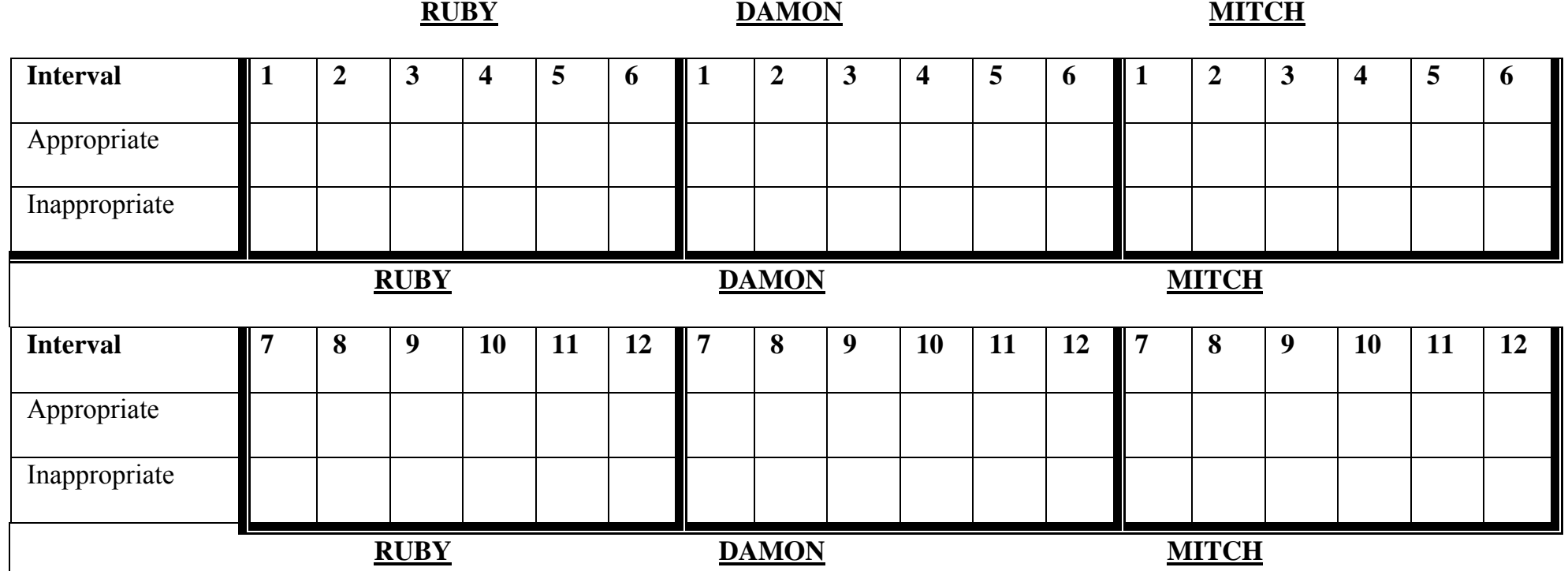

\begin{tabular}{|l||l|l|l|l|l|l||l|l|l|l|l|l||l|l|l|l|l|l|l|}
\hline Interval & 13 & 14 & 15 & 16 & 17 & 18 & 13 & 14 & 15 & 16 & 17 & 18 & 13 & 14 & 15 & 16 & 17 & 18 \\
\hline Appropriate & & & & & & & & & & & & & \\
\hline Inappropriate & & & & & & & & & & & & & & \\
\hline
\end{tabular}

Inappropriate Behaviors: whining, crying, yelling, destructiveness, aggressive behavior, negativism, self-stimulation, demanding attention, disruptive behavior, talking out of order, being out of area.

\begin{tabular}{|c|c|c|c|c|c|c|c|c|c|c|c|c|c|c|c|c|c|c|}
\hline Teacher Interval & 1 & 2 & 3 & 4 & 5 & 6 & 7 & 8 & 9 & 10 & 11 & 12 & 13 & 14 & 15 & 16 & 17 & 18 \\
\hline T. Labeled Praise & & & & & & & & & & & & & & & & & & \\
\hline T. Unlab. Praise & & & & & & & & & & & & & & & & & & \\
\hline T. Criticism & & & & & & & & & & & & & & & & & & \\
\hline Interval & 19 & 20 & 21 & 22 & 23 & 24 & 25 & 26 & 27 & 28 & 29 & 30 & 31 & 32 & 33 & 34 & 35 & 36 \\
\hline T. Labeled Praise & & & & & & & & & & & & & & & & & & \\
\hline T. Unlab. Praise & & & & & & & & & & & & & & & & & & \\
\hline T. Criticism & & & & & & & & & & & & & & & & & & \\
\hline Interval & 37 & 38 & 39 & 40 & 41 & 42 & 43 & 44 & 45 & 46 & 47 & 48 & 49 & 50 & 51 & 52 & 53 & 54 \\
\hline T. Labeled Praise & & & & & & & & & & & & & & & & & & \\
\hline T. Unlab. Praise & & & & & & & & & & & & & & & & & & \\
\hline T. Criticism & & & & & & & & & & & & & & & & & & \\
\hline
\end{tabular}


Behavioral Observation Coding Sheet

Coder:

Teacher:

Date:

Time:

Ruby:

Damon:

Mitch:

MITCH

$\underline{\text { RUBY }}$ DAMON

\begin{tabular}{|l||l|l|l|l|l|l||l|l|l|l|l|l||l|l|l|l|l|l|l|}
\hline Interval & 19 & 20 & 21 & 22 & 23 & 24 & 19 & 20 & 21 & 22 & 23 & 24 & 19 & 20 & 21 & 22 & 23 & 24 \\
\hline Appropriate & & & & & & & & & & & & & & \\
\hline Inappropriate & & & & & & & & & & & & & & \\
\hline \hline
\end{tabular}

\begin{tabular}{|l||l|l|l|l|l|l||l|l|l|l|l|l||l|l|l|l|l|l|l|}
\hline Interval & 25 & 26 & 27 & 28 & 29 & 30 & 25 & 26 & 27 & 28 & 29 & 30 & 25 & 26 & 27 & 28 & 29 & 30 \\
\hline Appropriate & & & & & & & & & & & & & \\
\hline Inappropriate & & & & & & & & & & & & & \\
\hline
\end{tabular}

\begin{tabular}{|l||l|l|l|l|l|l||l|l|l|l|l|l||l|l|l|l|l|l|l|}
\hline Interval & 31 & 32 & 33 & 34 & 35 & 36 & 31 & 32 & 33 & 34 & 35 & 36 & 31 & 32 & 33 & 34 & 35 & 36 \\
\hline Appropriate & & & & & & & & & & & & & & & \\
\hline Inappropriate & & & & & & & & & & & & & & & \\
\hline
\end{tabular}

Inappropriate Behaviors: whining, crying, yelling, destructiveness, aggressive behavior, negativism, self-stimulation, demanding attention, disruptive behavior, talking out of order, being out of area.

\begin{tabular}{|c|c|c|c|c|c|c|c|c|c|c|c|c|c|c|c|c|c|c|}
\hline Teacher Interval & 55 & 56 & 57 & 58 & 59 & 60 & 61 & 62 & 63 & 64 & 65 & 66 & 67 & 68 & 69 & 70 & 71 & 72 \\
\hline T. Labeled Praise & & & & & & & & & & & & & & & & & & \\
\hline T. Unlab. Praise & & & & & & & & & & & & & & & & & & \\
\hline T. Criticism & & & & & & & & & & & & & & & & & & \\
\hline Interval & 73 & 74 & 75 & 76 & 77 & 78 & 79 & 80 & 81 & 82 & 83 & 84 & 85 & 86 & 87 & 88 & 89 & 90 \\
\hline T. Labeled Praise & & & & & & & & & & & & & & & & & & \\
\hline T. Unlab. Praise & & & & & & & & & & & & & & & & & & \\
\hline T. Criticism & & & & & & & & & & & & & & & & & & \\
\hline Interval & 91 & 92 & 93 & 94 & 95 & 96 & 97 & 98 & 99 & 100 & 101 & 102 & 103 & 104 & 105 & 106 & 107 & 108 \\
\hline T. Labeled Praise & & & & & & & & & & & & & & & & & & \\
\hline T. Unlab. Praise & & & & & & & & & & & & & & & & & & \\
\hline T. Criticism & & & & & & & & & & & & & & & & & & \\
\hline
\end{tabular}


Behavioral Observation Coding Sheet

Coder:

Teacher:

Date:

Time:

Ruby:

Damon:

Mitch:

$\underline{\text { MITCH }}$

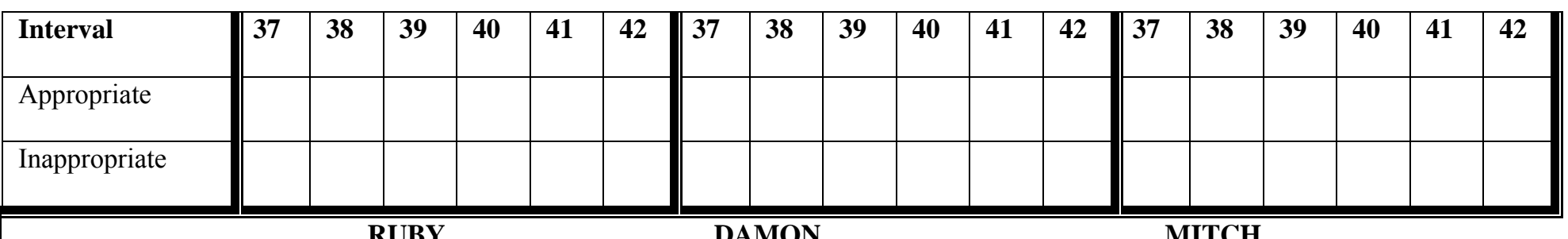

\begin{tabular}{|l||l|l|l|l|l|l||l|l|l|l|l|l||l|l|l|l|l|l|l|l|}
\hline Interval & 43 & 44 & 45 & 46 & 47 & 48 & 43 & 44 & 45 & 46 & 47 & 48 & 43 & 44 & 45 & 46 & 47 & 48 \\
\hline Appropriate & & & & & & & & & & & & & \\
\hline Inappropriate & & & & & & & & & & & & \\
\hline & $\underline{\text { DUBY }}$
\end{tabular}

\begin{tabular}{|l||l|l|l|l|l|l||l|l|l|l|l|l||l|l|l|l|l|l|l|}
\hline Interval & 49 & 50 & 51 & 52 & 53 & 54 & 49 & 50 & 51 & 52 & 53 & 54 & 49 & 50 & 51 & 52 & 53 & 54 \\
\hline Appropriate & & & & & & & & & & & & & & \\
\hline Inappropriate & & & & & & & & & & & & & & & \\
\hline
\end{tabular}

Inappropriate Behaviors: whining, crying, yelling, destructiveness, aggressive behavior, negativism, self-stimulation, demanding attention, disruptive behavior, talking out of order, being out of area.

\begin{tabular}{|c|c|c|c|c|c|c|c|c|c|c|c|c|c|c|c|c|c|c|}
\hline Teacher Interval & 109 & 110 & 111 & 112 & 113 & 114 & 115 & 116 & 117 & 118 & 119 & 120 & 121 & 122 & 123 & 124 & 125 & 126 \\
\hline T. Labeled Praise & & & & & & & & & & & & & & & & & & \\
\hline T. Unlab. Praise & & & & & & & & & & & & & & & & & & \\
\hline T. Criticism & & & & & & & & & & & & & & & & & & \\
\hline Interval & 127 & 128 & 129 & 130 & 131 & 132 & 133 & 134 & 135 & 136 & 137 & 138 & 139 & 140 & 141 & 142 & 143 & 144 \\
\hline T. Labeled Praise & & & & & & & & & & & & & & & & & & \\
\hline T. Unlab. Praise & & & & & & & & & & & & & & & & & & \\
\hline T. Criticism & & & & & & & & & & & & & & & & & & \\
\hline Interval & 145 & 146 & 147 & 148 & 149 & 150 & 151 & 152 & 153 & 154 & 155 & 156 & 157 & 158 & 159 & 160 & 161 & 162 \\
\hline T. Labeled Praise & & & & & & & & & & & & & & & & & & \\
\hline T. Unlab. Praise & & & & & & & & & & & & & & & & & & \\
\hline T. Criticism & & & & & & & & & & & & & & & & & & \\
\hline
\end{tabular}




\section{Behavioral Observation Coding Sheet}

Coder:

Teacher:

Date:

Time:

Ruby:

Damon:

Mitch:

MITCH

$\underline{\text { RUBY }}$ DAMON

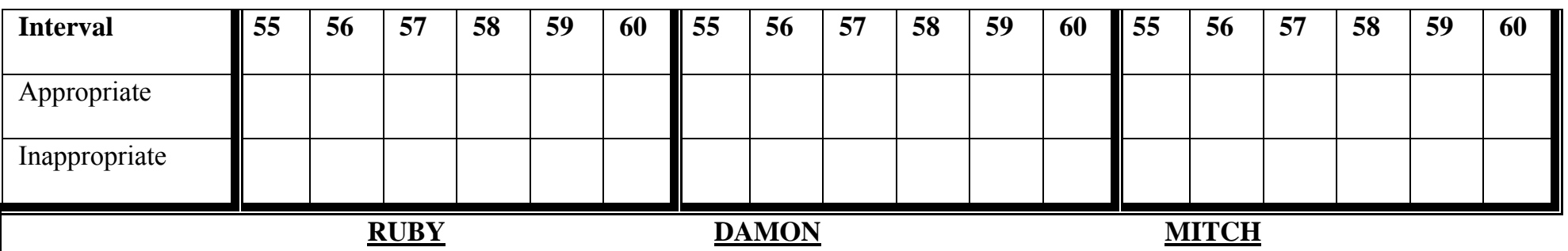

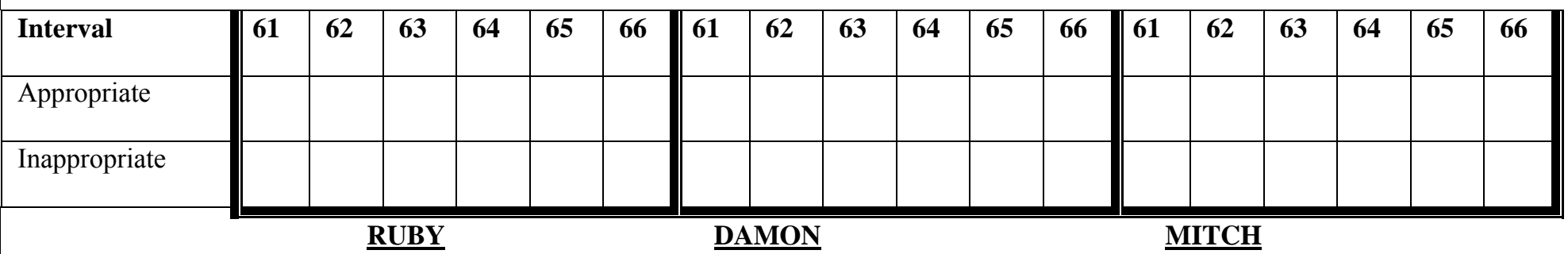

\begin{tabular}{|l||l|l|l|l|l|l||l|l|l|l|l|l||l|l|l|l|l|l|l|}
\hline Interval & 67 & 68 & 69 & 70 & 71 & 72 & 67 & 68 & 69 & 70 & 71 & 72 & 67 & 68 & 69 & 70 & 71 & 72 \\
\hline Appropriate & & & & & & & & & & & & & & & \\
\hline Inappropriate & & & & & & & & & & & & & & & & & \\
\hline
\end{tabular}

Inappropriate Behaviors: whining, crying, yelling, destructiveness, aggressive behavior, negativism, self-stimulation, demanding attention, disruptive behavior, talking out of order, being out of area.

\begin{tabular}{|c|c|c|c|c|c|c|c|c|c|c|c|c|c|c|c|c|c|c|}
\hline Teacher Interval & 163 & 164 & 165 & 166 & 167 & 168 & 169 & 170 & 171 & 172 & 173 & 174 & 175 & 176 & 177 & 178 & 179 & 180 \\
\hline T. Labeled Praise & & & & & & & & & & & & & & & & & & \\
\hline T. Unlab. Praise & & & & & & & & & & & & & & & & & & \\
\hline T. Criticism & & & & & & & & & & & & & & & & & & \\
\hline Interval & 181 & 182 & 183 & 184 & 185 & 186 & 187 & 188 & 189 & 190 & 191 & 192 & 193 & 194 & 195 & 196 & 197 & 198 \\
\hline T. Labeled Praise & & & & & & & & & & & & & & & & & & \\
\hline T. Unlab. Praise & & & & & & & & & & & & & & & & & & \\
\hline T. Criticism & & & & & & & & & & & & & & & & & & \\
\hline Interval & 199 & 200 & 201 & 202 & 203 & 204 & 205 & 206 & 207 & 208 & 208 & 210 & 211 & 212 & 213 & 214 & 215 & 216 \\
\hline T. Labeled Praise & & & & & & & & & & & & & & & & & & \\
\hline T. Unlab. Praise & & & & & & & & & & & & & & & & & & \\
\hline T. Criticism & & & & & & & & & & & & & & & & & & \\
\hline
\end{tabular}




\section{Behavioral Observation Coding Sheet}

Coder:

Teacher:

Date:

Time:

Ruby:

Damon:

Mitch

$\underline{\text { RUBY }}$ DAMON

MITCH

\begin{tabular}{|l||l|l|l|l|l|l||l|l|l|l|l|l||l|l|l|l|l|l|l|}
\hline Interval & $\mathbf{7 3}$ & $\mathbf{7 4}$ & $\mathbf{7 5}$ & $\mathbf{7 6}$ & $\mathbf{7 7}$ & $\mathbf{7 8}$ & $\mathbf{7 3}$ & $\mathbf{7 4}$ & $\mathbf{7 5}$ & $\mathbf{7 6}$ & $\mathbf{7 7}$ & $\mathbf{7 8}$ & $\mathbf{7 3}$ & $\mathbf{7 4}$ & $\mathbf{7 5}$ & $\mathbf{7 6}$ & $\mathbf{7 7}$ & $\mathbf{7 8}$ \\
\hline Appropriate & & & & & & & & & & & & & & \\
\hline Inappropriate & & & & & & & & & & & & & \\
\hline \hline
\end{tabular}

RUBY

DAMON

$\underline{\text { MITCH }}$

\begin{tabular}{|l||l|l|l|l|l|l||l|l|l|l|l|l||l|l|l|l|l|l|l|}
\hline Interval & $\mathbf{7 9}$ & $\mathbf{8 0}$ & $\mathbf{8 1}$ & $\mathbf{8 2}$ & $\mathbf{8 3}$ & $\mathbf{8 4}$ & $\mathbf{7 9}$ & $\mathbf{8 0}$ & $\mathbf{8 1}$ & $\mathbf{8 2}$ & $\mathbf{8 3}$ & $\mathbf{8 4}$ & $\mathbf{7 9}$ & $\mathbf{8 0}$ & $\mathbf{8 1}$ & $\mathbf{8 2}$ & $\mathbf{8 3}$ & $\mathbf{8 4}$ \\
\hline Appropriate & & & & & & & & & & & & & & \\
\hline Inappropriate & & & & & & & & & & & & & & & \\
\hline
\end{tabular}

Inappropriate Behaviors: whining, crying, yelling, destructiveness, aggressive behavior, negativism, self-stimulation, demanding attention, disruptive behavior, talking out of order, being out of area.

\begin{tabular}{|l||l|l|l|l|l|l|}
\hline Teacher Interval & 217 & $\mathbf{2 1 8}$ & $\mathbf{2 1 9}$ & $\mathbf{2 2 0}$ & $\mathbf{2 2 1}$ & $\mathbf{2 2 2}$ \\
\hline T. Labeled Praise & & & & & & \\
\hline T. Unlab. Praise & & & & & & \\
\hline T. Criticism & & & & & & \\
\hline \hline Interval & 235 & 236 & 237 & $\mathbf{2 3 8}$ & $\mathbf{2 3 9}$ & $\mathbf{2 4 0}$ \\
\hline T. Labeled Praise & & & & & & \\
\hline T. Unlab. Praise & & & & & & \\
\hline T. Criticism & & & & & & \\
\hline
\end{tabular}

Child total \% appropriate:

Teacher total \% U.L.P.:

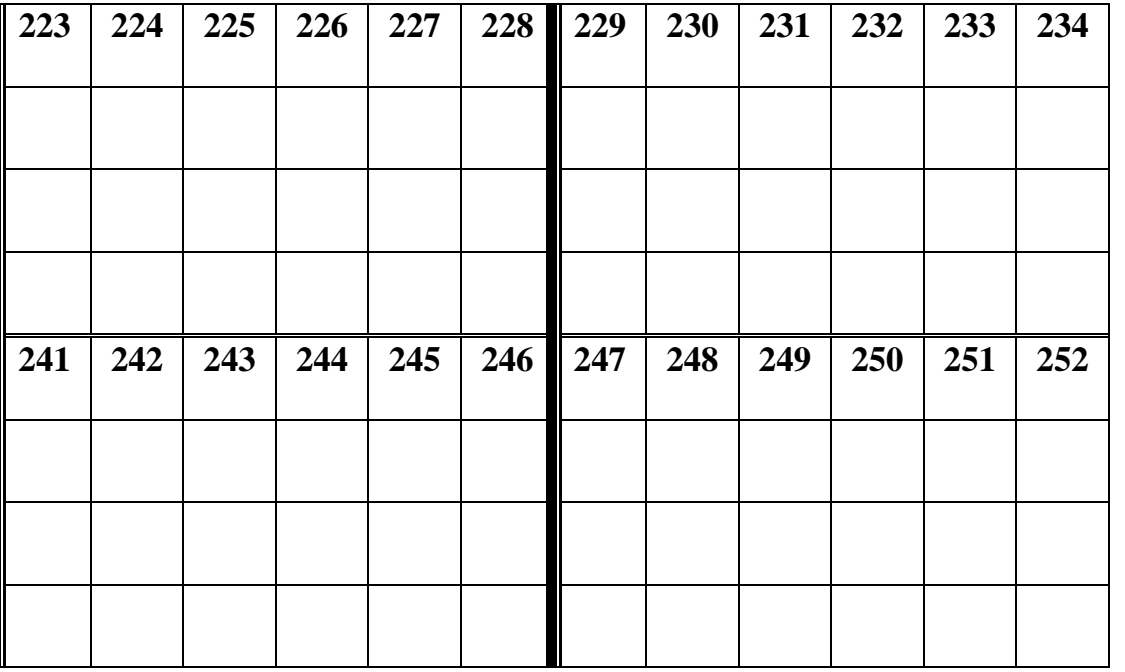

Child total \% inapprop.: Teacher total \% L.P.:

Teacher total $\%$ criticisms 
Appendix G

Classroom Management Rating

Teacher's Name

Day

Date

\section{How manageable was your class today?}

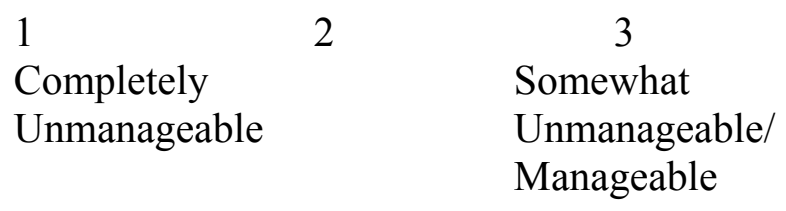

4

5

Completely

Manageable 
Appendix $\mathrm{H}$

Daily Time-Out Log

Teacher's Name

Day

Date

Record each time out that occurred in your classroom today.

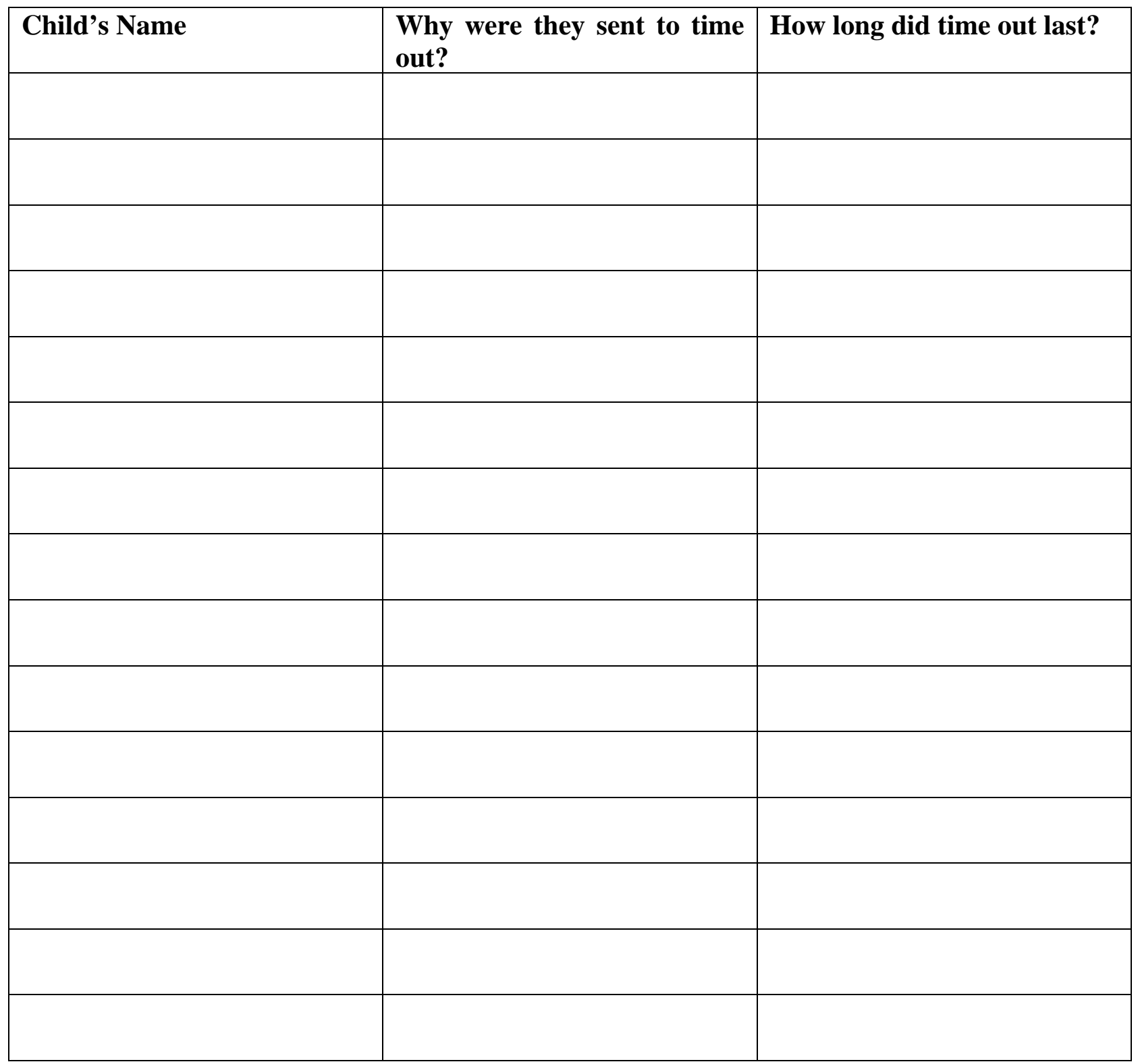




\section{Appendix I}

Intervention Rating Profile

Teacher Name:

Date:

Program Evaluated (please circle): Current Strategies $\quad$ Response Cost Level System

\section{Instructions}

Read each item below carefully and circle one number to indicate how much you agree/disagree with the statement as it applies to the program circled above.

\section{Strongly \\ Disagree}

\section{Strongly}

Agree

1. Most teachers would find the intervention suitable for behavior

$\begin{array}{llllll}1 & 2 & 3 & 4 & 5 & 6\end{array}$
problems in the classroom.

2. Most teachers would find this intervention appropriate for behavior

$\begin{array}{llllll}1 & 2 & 3 & 4 & 5 & 6\end{array}$
problems in addition to those that I have experienced in the classroom.

3. Children's behavior problems in the classroom are severe enough to warrant the use of this intervention.

4. This intervention should prove effective $\quad \begin{array}{llllllll}1 & 2 & 3 & 4 & 5 & 6\end{array}$ in changing children's problem behavior.

5. This would be an acceptable intervention $\quad \begin{array}{llllllll}1 & 2 & 3 & 4 & 5 & 6\end{array}$ for children's problem behavior.

6. Overall, the intervention would be beneficial for children.

7. I would be willing to use this intervention in the classroom setting.

8. This intervention would be appropriate $\quad \begin{array}{llllllll}1 & 2 & 3 & 4 & 5 & 6\end{array}$ for use before making a referral.

9. This intervention would not result $\begin{array}{llllll}1 & 2 & 3 & 4 & 5 & 6\end{array}$ in negative side effects for children. 
Strongly

Disagree
Strongly

Agree

$\begin{array}{llllll}1 & 2 & 3 & 4 & 5 & 6\end{array}$

$\begin{array}{llllll}1 & 2 & 3 & 4 & 5 & 6\end{array}$

11. This intervention would not be considered a "last resort."

12. This intervention is practical in the amount of time required for parent contact.

13. This intervention is practical in

$\begin{array}{llllll}1 & 2 & 3 & 4 & 5 & 6\end{array}$
the amount of time required for contact with day care staff.

14. This intervention is practical in the amount of time required for record keeping.

15. This intervention is practical in the amount of out-of-day care time required for implementation.

16. This intervention would not be difficult to implement in a classroom with 30 students.

17. This intervention would not be disruptive to students.

18. It would not be difficult to use this intervention and still meet the needs of children in the classroom.

19. Teachers are likely to use this intervention $1 \begin{array}{llllllll}1 & 2 & 3 & 4 & 5 & 6\end{array}$ because it requires little technical skill.

20. Teachers are likely to use this intervention because it requires little training to implement effectively. $\begin{array}{llllll}1 & 2 & 3 & 4 & 5 & 6\end{array}$

$\begin{array}{llllll}1 & 2 & 3 & 4 & 5 & 6\end{array}$

$\begin{array}{llllll}1 & 2 & 3 & 4 & 5 & 6\end{array}$

$\begin{array}{llllll}1 & 2 & 3 & 4 & 5 & 6\end{array}$

$\begin{array}{llllll}1 & 2 & 3 & 4 & 5 & 6\end{array}$ 
Appendix $\mathbf{J}$

\section{Parent Interview}

Parent's Name: Child's Name:

Date:

\section{Instructions}

We are interested in how parents feel about different classroom management strategies. Read each item below carefully and circle one number to indicate how acceptable/unacceptable that you feel each strategy is to use in the classroom to manage behavior.

\section{Very \\ Unacceptable}

1. The use of a Level System in which children move up for appropriate behavior and move down for inappropriate behavior. At certain times throughout the day, the children who are in the sunny zone receive a reward.

2. Your child does not receive the reward from the level system for 2 days in a row.

3. Posting the level system on the wall so that everyone who enters the room can see it.

4. Praising children for appropriate behavior. For example, "Good job sharing your toy!"

5. The use of "when-then" statements. For example, "When you sit on your carpet, then I will read the book."

6. Using redirection, such as moving a child to another area or getting them interested in another activity, when mild misbehavior occurs (like arguing).

7. Giving children "two-choices" with logical consequences for inappropriate behavior. For example, "You have two-choices. You can either play gently with the blocks, or I will put the blocks away."
Very

Acceptable 
8. The use of a "calm down area" which is a $\begin{array}{llllll}1 & 2 & 3 & 4 & 5 & 6\end{array}$ place in the room, away from other children, where children go when they are becoming too hyper to take part in a quiet activity (like reading or doing a puzzle) until they calm down enough to return to the regular class activity.

9. The use of time-out in a chair in the room for dangerous or destructive behavior or repeated noncompliance for a maximum amount of time of 3 minutes. Children are given a "two-choices" warning (see above) before they go to time-out so that they can correct their misbehavior.

10. The current classroom management strategies $\quad \begin{array}{llllllll}1 & 2 & 3 & 4 & 5 & 6\end{array}$ that the teacher and teacher's aide are using.

11. Response cost in which children lose smiley $\quad \begin{array}{lllllll}1 & 2 & 3 & 4 & 5 & 6\end{array}$ faces for inappropriate behavior at certain times throughout the day and the children who have at least one smiley face left receive a reward.

12. Please list all of the positive things about the level system.

13. Please list all of the negative things about the level system.

14. Please list all of the positive things about time-out.

15. Please list all of the negative things about time-out.

16. Please list all the positive things about response cost. 
17. Please list all the negative things about response cost.

18. How do you feel about modifying expectations for individual children while using the level system so that children with behavior problems receive the reward about the same amount that the other children do? For example, most children in the classroom may be expected to sit on their carpet during reading time, and they may not move up a level. However, if a child has trouble sitting on his/her carpet, that child may be rewarded (move up a level) for sitting on his/her carpet until the child is able to sit just like the other children. 


\section{Appendix K}

\section{Parent Script For Response Cost}

** If this is the first script, say:

I will be describing 2 procedures that can be used to decrease disruptive behavior in the classroom. Once I have described both procedures, please indicate the one procedure you would prefer to be used in your child's classroom to help the teacher manage behavior. This information will be used to understand parents' attitudes about behavior management plans. It will not necessarily affect your child's teacher's plan for behavior management. This first procedure is a response cost.

**If this is the second script, say:

The next procedure is response cost.

- The response cost program provides a delayed reward for the absence of inappropriate behavior and an immediate warning and a minor consequence (e.g., removal of a smiley face) for inappropriate behavior.

- Each child is assigned a shape with his or her initials on it. The board is posted in the class where each child can easily see the board (show parent the board).

- All shapes are placed in the top-most level of the board at the beginning.

- Children's shapes would be moved down a level for inappropriate behavior (i.e., not following class rules, noncompliance, hurting, or destruction of property).

- Children first would be given a warning for inappropriate behavior and then if they did not begin to behave appropriately, the teacher would move the shape down one level. For example, the teacher would say, "You have two choices. You can either pick up the blocks or your shape will be moved down one level." Alternatively, the teacher could use a visual warning without words (show parent visual signal) and simply say the child's name. For example, the teacher would say, "Jacob," and show the two choice warning signal to the child. Then if the child did not begin to behave appropriately, the teacher would move the shape down one level.

- Children would not be given a warning for hurting others (e.g., hitting another child) or destruction of property (e.g., ripping pages out of a book); their shape would simply be moved down. The teacher has the option of adding a consequence (e.g., time-out) when a child's shape is moved down for these behaviors.

- At the end of a period of approximately 40 minutes, the teacher would give out the rewards. Children whose shapes are in the sunny zone of the board would receive the same reward (e.g., hand stamp, play charades), and children whose shapes are in the cloudy zone of the board would not receive the reward. 
- The rewards are printed on cards. The teacher would give out the rewards at least once during the period of approximately 40 minutes. Each reward card should be used once before any reward card is used again.

- After the reward was given to the children, all children's shapes would be replaced to the top-most level of the board, and a new period would begin where children could earn a reward. The children essentially would be starting over for the next period.

- The response cost should be used for all transitions (e.g., moving from circle time to structured activity, play time to clean-up). In other words, the teacher should refer to the response cost board if a child did not comply with directions during every transition.

** If this is the last script, ask parent:

Now that I have descried the 2 procedures that can be used to decrease disruptive behavior in the classroom, which procedure would you choose to be used by the teacher in your child's classroom? 


\section{Child Script for Response Cost}

** If this is the first script, say:

I will be telling you about 2 different things your teacher could use to help kids be good. After I tell you about these 2 things, I want you to pick which one you would want your teacher to use in your class. The first one is called response cost.

**If this is the second script, say:

The second thing your teacher could use to help kids be good is a response cost.

- Every child has his or her own shape with his or her initials on it. The board is put in the class somewhere everyone could see it (show child the board).

- Everyone's shapes would start out up here at the top (point to the top level).

- Your shape would be moved down one level for bad behavior (i.e., not following class rules, not doing what the teacher tells you to do, hurting someone else, or tearing things up).

- The teacher would warn you were doing a bad behavior. If you kept doing the bad behavior, the teacher would move your shape down one level. For example, the teacher would say, "You have two choices. You can either pick up the blocks or your shape will be moved down one level." Or the teacher would do this (show child visual signal) and say your name. This means that you could either stop doing the bad behavior or your shape would be moved down.

- The teacher would move your shape down without warning you if you hurt someone or you tore up something. You could also be put in time-out and your shape moved down if you hurt someone or tore up something.

- After about 40 minutes, everyone whose shape is in the sunny zone of the board (point to sunny zone) would get a reward (e.g., hand stamp, play charades). But anyone whose shape was in the cloudy zone of the board (point to cloudy zone) after about 40 minutes would not get the reward.

- The rewards are written on cards and your teacher would pick a card. Whatever reward was on the card your teacher picked would be the reward you would get.

- After you get the reward, everyone's shape would be put back in this top level (point to top level) on the board, and everyone would get to start over and try to earn the next reward. 
** If this is the first script, say:

I want you to tell me how you feel about this smiley face board using these faces (show child faces rating). This really sad face (point to the saddest face on the rating) means that you really do not like something. This really happy face (point to happiest face on rating scale) means that you really like something. This face (point to second saddest face) means that you don't like something a little bit. This face (point to second happiest face) means that you like something a little bit. What face would you pick to tell me how you would feel if a kid kicked you in the leg? [child should point to sad face]. What face would you pick to tell me how you would feel if you got 100 presents for Christmas? [child should point to happy face]. What face would you pick to tell me how would feel if you had your favorite food for dinner? [child should point to second happy face]. What face would you pick to tell me how you would feel about hurting your big toe? [child should point to next-to-last sad face].

*If it appears child does not understand the rating system, give additional examples until child appears to understand the system. Once child can understand the rating system, ask the child: What face would you pick to tell me how you would feel if your teacher used this board in your class to help you be good?

** If this is the last script, ask child:

Which one [point to the 2 boards] do you like best? 


\section{Parent Script For the Level System}

** If this is the first script, say:

I will be describing 2 procedures that can be used to decrease disruptive behavior in the classroom. Once I have described both procedures, please indicate the one procedure you would prefer to be used in your child's classroom to help the teacher manage behavior. This information will be used to understand parents' attitudes about behavior management plans. It will not necessarily affect your child's teacher's plan for behavior management. This first procedure is a type of token reinforcement system called the Level System.

**If this is the second script, say:

The next procedure is a type of token reinforcement system called the Level System.

- Each child in the class would have a shape on the board (show parent the Level System) and the board would be placed in the room so that children could see where their shape was on the board. The board would remain visible during the entire class period.

- At the beginning of the periods of approximately 40 minutes, the children's shapes would start out in the neutral zone of the Level System (point out neutral zone to parent).

Shapes would then be moved up the Level System for appropriate behavior (e.g., sitting correctly, putting coat away, following class rules) and down the Level System for inappropriate behavior (e.g., not following class rules, noncompliance).

- When children are moved up a level, the teacher would give those children a labeled praise (i.e., specific praise such as "Thank you for sitting in your seat") for appropriate behavior. The teacher must compliment the children with a specific praise each time their shape is moved up. That way children know exactly which behaviors the teacher likes and which behaviors they should do more of in the future if they want to move up a level.

- Children first would be given a warning for inappropriate behavior, and then if they did not begin to behave appropriately, their shape would be moved down a level. For example, the teacher would say, "You have two choices. You can either put the crayons in the basket, or you will move down a level." Alternatively, the teacher could use the visual two choice warning signal (show parent visual signal) without words and simply say the child's name. Then, if the child did not begin to behave appropriately, the teacher would move the child's shape down a level.

- Children would not be given a warning for hurting others (e.g., hitting other children and making them cry) or destruction of property (e.g., tearing up other children's work); they simply are moved down a level. The teacher would have the option of adding a consequence (e.g., time-out) when the child was moved down for these behaviors.

- If the child continued to misbehave after being moved down a level, the teacher would give the child another warning if appropriate (i.e., if the child hasn't hurt anyone or destroyed property), and if the child still continued to misbehave, the child's shape would be moved down a level again. If the misbehavior continued after the child's shape had 
been moved down 2 times, the teacher could provide another consequence, such as timeout, that would typically be given in the classroom for that behavior.

- At the end of a period of approximately 40 minutes, the teacher would give out the rewards. All children in the sunny zone (point out sunny zone) would receive the same reward (e.g., hand stamp, play charades) and all children in the cloudy zone (point out cloudy zone) would not receive the reward.

- The rewards are printed on cards and the teacher would give out the rewards at least once during the period of approximately 40 minutes.

- Each reward would be used once before any reward card was used again.

- After the children received the reward, all of the children's shapes would be placed back in the neutral zone (point out neutral zone), and a new period would begin where the children could earn the next reward.

- If s child's shape was in the $3^{\text {rd }}$ cloudy level (point out $3^{\text {rd }}$ cloudy level) of the system, the teacher would take the child aside and discuss the rules with that child. In addition, the teacher could lower expectations for that child and focus on small positive behaviors so that the child would receive positive feedback and be able to move up the Level System. For example, if a child was behaving aggressively, the teacher would tell the child that if he or she could play gently, the shape would be moved up a level.

- If a child's shape was in the $3^{\text {rd }}$ sunny level of the system (point out $3^{\text {rd }}$ sunny level), the child would still receive labeled praises for behaving nicely even though the child's shape could move up any more.

** If this is the last script, ask parent:

Now that I have descried the 2 procedures that can be used to decrease disruptive behavior in the classroom, which procedure would you choose to be used by the teacher in your child's classroom? 


\section{Child Script For the Level System}

**If this is the first script, say:

I will be telling you about 2 different things your teacher could use to help kids be good. After I tell you about these 2 things, I want you to pick which one you would want your teacher to use in your class. The first one is called the Level System.

**If this is the second script, say:

The second thing your teacher could use to help kids be good at school is called the Level System (show child Level System).

- Every child in the class would have a shape on the board (show child the Level System) and this board would be put up in the room so everyone could always see where their shape was on the board.

- Everyone's shape would start out in this blank zone of the Level System (point out neutral zone to child). Shapes would be moved up the Level System for good behavior (e.g., sitting nicely, putting coat away, following class rules) and shapes would be moved down the Level System for bad behavior (e.g., not following class rules, noncompliance).

- When your teacher moved your shape up a level, the teacher would tell you what you did that was good. If you shared toys with a friend, the teacher would move your shape up and tell you that you did a good job of sharing. Your teacher would always say something nice about your behavior when she moved your shape up a level.

- Your teacher would warn you when you did a bad behavior and if you kept doing that bad behavior your shape would be moved down a level. If you did not share toys, your teacher would say, "You have two choices. You can either share the toys, or you will move down a level." Or the teacher would do this (show child visual signal) and say your name. This means that you could either stop doing the bad behavior or you would move down a level.

- The teacher would move your shape down a level without warning you if you hurt someone or you tore up something. You could also be put in time-out and moved down a level if you hurt someone or tore up something.

- If you continued to misbehave after being moved down a level, your teacher would give you another warning and if you still misbehaved, your shape would be moved down a level again. If the bad behavior continued after your shape had been moved down 2 times, your teacher might give you a time-out.

- After about 40 minutes, everyone in the sunny zone (point out sunny zone to child) would get a reward (e.g., hand stamp, play charades). But anyone whose shape was in the cloudy zone (point out cloudy zone to child) after about 40 minutes, you would not get the reward. 
- The rewards are printed on cards and children could get one reward about every 40 minutes if their shape was in the sunny zone. The rewards are written on cards and your teacher would pick a card. Whatever reward was on the card your teacher picked would be the reward everyone in the sunny zone would get.

- After you get the reward, everyone's shape would be put back in the empty space, and everyone would get to start over and try to earn the next reward.

**If this is the first script, say:

I want you to tell me how you feel about this smiley face board using these faces (show child faces rating). This really sad face (point to the saddest face on the rating) means that you really do not like something. This really happy face (point to happiest face on rating scale) means that you really like something. This face (point to second saddest face) means that you don't like something a little bit. This face (point to second happiest face) means that you like something a little bit. What face would you pick to tell me how you would feel if a kid kicked you in the leg? [child should point to sad face]. What face would you pick to tell me how you would feel if you got 100 presents for Christmas? [child should point to happy face]. What face would you pick to tell me how would feel if you had your favorite food for dinner? [child should point to second happy face]. What face would you pick to tell me how you would feel about hurting your big toe? [child should point to next-to-last sad face].

*If it appears child does not understand the rating system, give additional examples until child appears to understand the system. Once child can understand the rating system, ask the child: What face would you pick to tell me how you would feel if your teacher used the Level System in your class to help you be good?

** If this is the last script, ask child:

Which one [point to the 2 boards] do you like best? 
Child Ratings of Response Cost and the Level System

\section{RESPONSE COST}
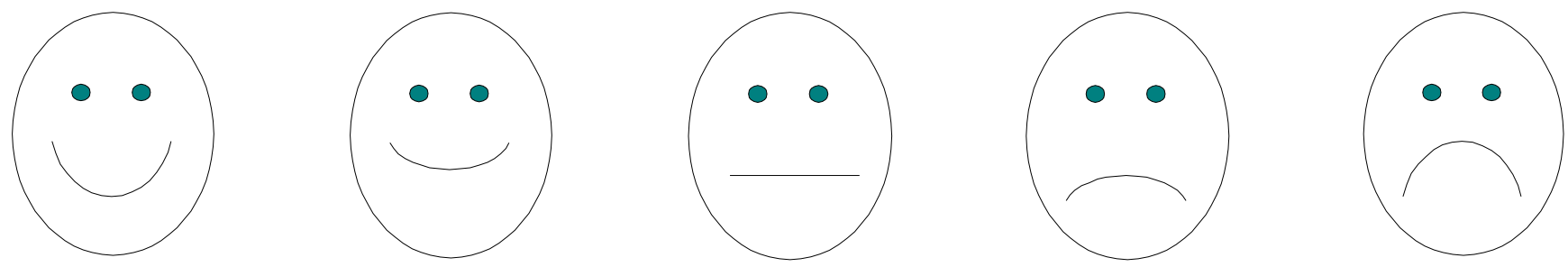

LEVEL SYSTEM
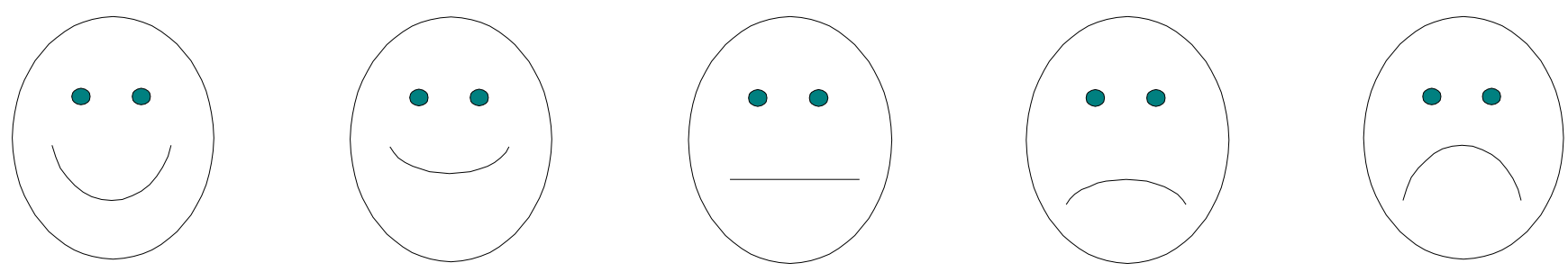


\section{Appendix L}

\section{Response Cost Treatment Integrity Checklist}

Teacher: Coder: Date: Time:

Question

Response

Response for for Teacher Teacher's Aide

\begin{tabular}{|c|c|c|}
\hline $\begin{array}{l}\text { 1. The response cost board is hung in a location visible to the } \\
\text { children. }\end{array}$ & Yes No N/A & Yes No N/A \\
\hline 2. Each child has a shape with his or her initials on it. & Yes No N/A & Yes No N/A \\
\hline $\begin{array}{l}\text { 3. Each child's shape is in the top-most level of the board at the } \\
\text { beginning of the interval. }\end{array}$ & Yes No N/A & Yes $\quad$ No $\mathrm{N} / \mathrm{A}$ \\
\hline $\begin{array}{l}\text { 4. Teacher uses a warning signal for the majority of inappropriate } \\
\text { behaviors in the classroom. }\end{array}$ & Yes No N/A & Yes No N/A \\
\hline $\begin{array}{l}\text { 5. Teacher follows through with moving a shape down a level } \\
\text { most of the time when a warning signal is given and the } \\
\text { behavior continues. }\end{array}$ & Yes No N/A & Yes No N/A \\
\hline $\begin{array}{l}\text { 6. Teacher uses a boring, monotonous tone of voice most of the } \\
\text { time when moving a shape down a level. }\end{array}$ & Yes No N/A & Yes No N/A \\
\hline $\begin{array}{l}\text { 7. Children are given a warning every time before a shape is } \\
\text { moved down (expect for hurting). }\end{array}$ & Yes No N/A & Yes No N/A \\
\hline $\begin{array}{l}\text { 8. No warning is given for hurting or destruction of property. } \\
\text { Shapes simply are moved down most of the time. }\end{array}$ & Yes No N/A & Yes No N/A \\
\hline $\begin{array}{l}\text { 9. If the children earn the reward, they are able to move to a } \\
\text { different or separate part of the room to participate. }\end{array}$ & Yes No N/A & Yes No N/A \\
\hline 10. The response cost is used for each major transition. & Yes No N/A & Yes No N/A \\
\hline $\begin{array}{l}\text { 11. Shapes are replaced to the top-most level on the board } \\
\text { following the reward. }\end{array}$ & Yes No N/A & Yes No N/A \\
\hline $\begin{array}{l}\text { 12. Teacher tells the children the reason why shapes are moved } \\
\text { down every time. }\end{array}$ & Yes No N/A & Yes No N/A \\
\hline 13. Rewards are administered at the end of the classroom activity. & Yes No N/A & Yes No N/A \\
\hline
\end{tabular}




\section{Appendix M}

The Level System Treatment Integrity Checklist

Teacher:

Coder:

Date:

Time:

Question

Response Response for

for Teacher Teacher's Aide

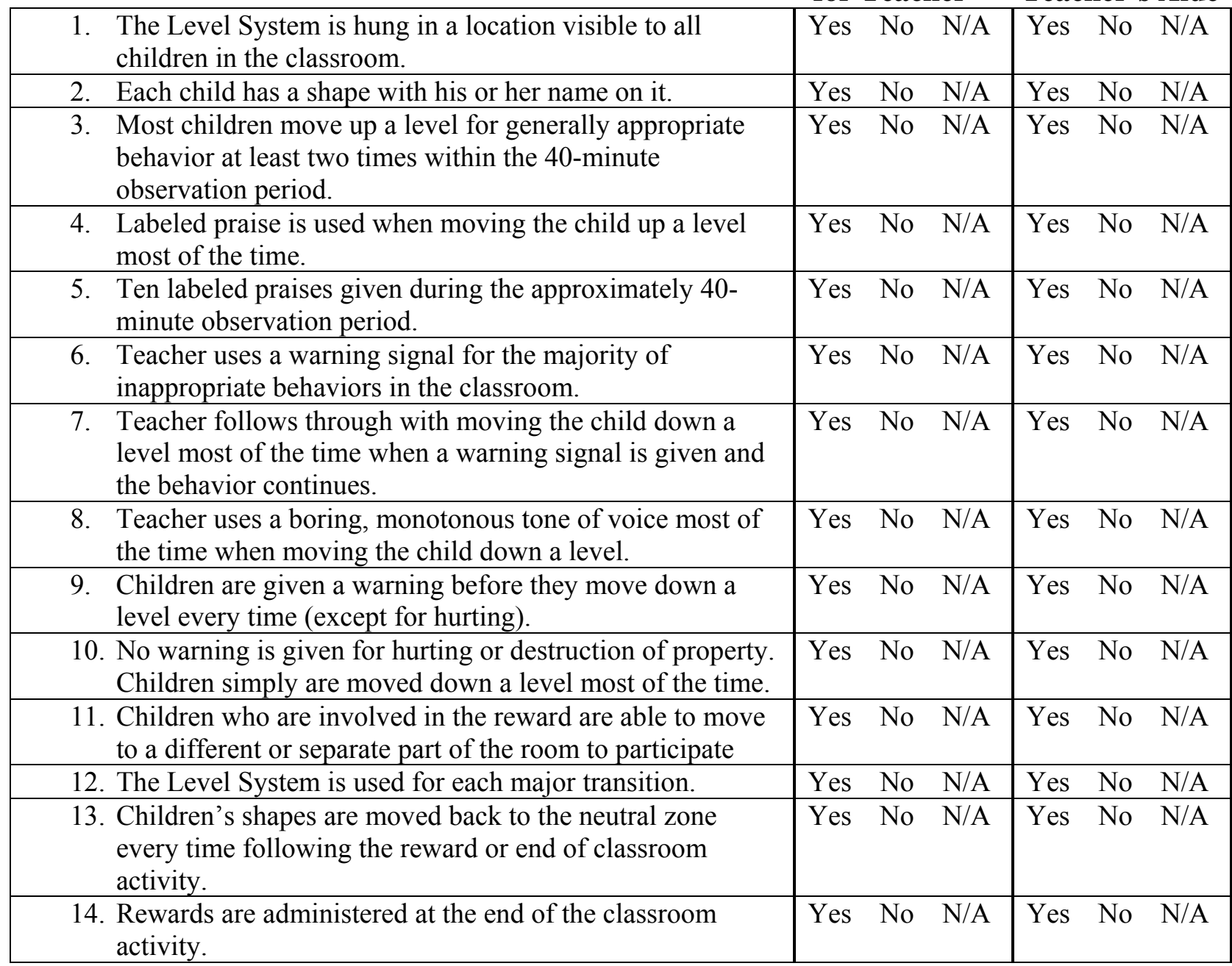




\section{Appendix N}

\section{Response Cost Manual}

The response cost will be used as a way to provide a delayed reward for the absence of inappropriate behavior and give an immediate warning and a minor consequence for inappropriate behavior.

To implement the response class for the whole class.

- Each child's assigned shape is placed on a board in the class where the children can easily see the board. All shapes begin in the top-most level of the board.

- Children's shapes are moved down a level for inappropriate behavior (i.e., not following class rules, noncompliance, hurting, destruction of property).

- Children first are given a warning for inappropriate behavior and then if they do not begin to behave appropriately, their shapes are moved down one level by the teacher. For example, the teacher would say, "You have two choices. You can either pick up the blocks or your shape will be moved down one level." Alternatively, the teacher can use a visual warning without words and simply say the child's name. For example, the teacher would say, "Jacob," and show the two choice warning signal to the child. Then if the child did not begin to behave appropriately, the teacher would move the child's shape down one level. If the child continues to exhibit inappropriate behavior once the shape is in the bottom level, regular classroom management strategies may be used.

- Children are not given a warning for hurting others (e.g., hitting another child) or destruction of property (e.g., ripping pages out of a book); their shape is simply moved down one level. The teacher has the option of adding a consequence when the child's shape is moved down for these behaviors.

- At the end of the approximately 40-minute observation period, the teacher should give out the rewards. Children whose shape is in the sunny zone of the board receive the reward (e.g., snack, activity) and children whose shape is in the cloudy zone of the board do not receive the reward; they simply continue engaging in regular classroom activities.

- The rewards are printed on the cards and all of the children receive the same reward. The teacher should give out the rewards at least once in the approximately 40-minute period.

- Each reward card should be used once before any reward card is used again. Place the used reward cards in the envelope so each teacher knows which cards have been used.

- After the reward is given to the children, all of the children's shapes are moved back to the top-most level of the board, and a new period begins where the child can earn a reward. The children essentially are starting over for the next period. 
- All of the children in the class should have equal access to the rewards. To ensure that the children are receiving the rewards with the same frequency:

o Expectations must be individualized for each child, so that some children do not lose a smiley face for leaving a few crayons on the table. These expectations should be increased when the child masters them.

o The teacher must complete the Daily Reward Log to monitor which children receive a reward or not. If some children continually are not receiving the reward, then that child's expectations must be lowered so that he or she may have access to the reward.

- The response cost should be used for all transitions (e.g., moving from circle time to structured activity, play time to clean-up). In other words, the teacher should refer to the response cost board if the child does not comply with directions during every transition. 


\section{Appendix O}

Daily Reward Log

Teacher's Name

Day

Date

Cross out the names of the children who did NOT receive the reward in your class today.

(Each child's name in the class is listed below.)

$1^{\text {st }}$ Reward $\quad 2^{\text {nd }}$ Reward $\quad 3^{\text {rd }}$ Reward $\quad 4^{\text {th }}$ Reward 
Table 1

CGI T-Scores of Participants per Condition

\begin{tabular}{cccc} 
& \multicolumn{3}{c}{ Participant } \\
Condition & Ruby & Damon & Mitch \\
Baseline & $>90$ & 63 & 57 \\
Response Cost & $>90$ & 62 & 58 \\
Level System & 89 & 44 & 54 \\
Follow-up & 59 & & 46
\end{tabular}




\section{Figure Captions}

Figure 1. Percent of intervals scored with inappropriate behavior exhibited by each participant. $\downarrow$ indicates stimulant medication implementation for Ruby and // indicates summer break.

Figure 2. Teacher report of daily class manageability ratings. // indicates summer break.

Figure 3. Teacher report of the number of time-outs administered daily. // indicates summer break.

Figure 4. Percentage of intervals scored with labeled praises, unlabeled praises, and criticisms exhibited by the teacher. // indicates summer break. 


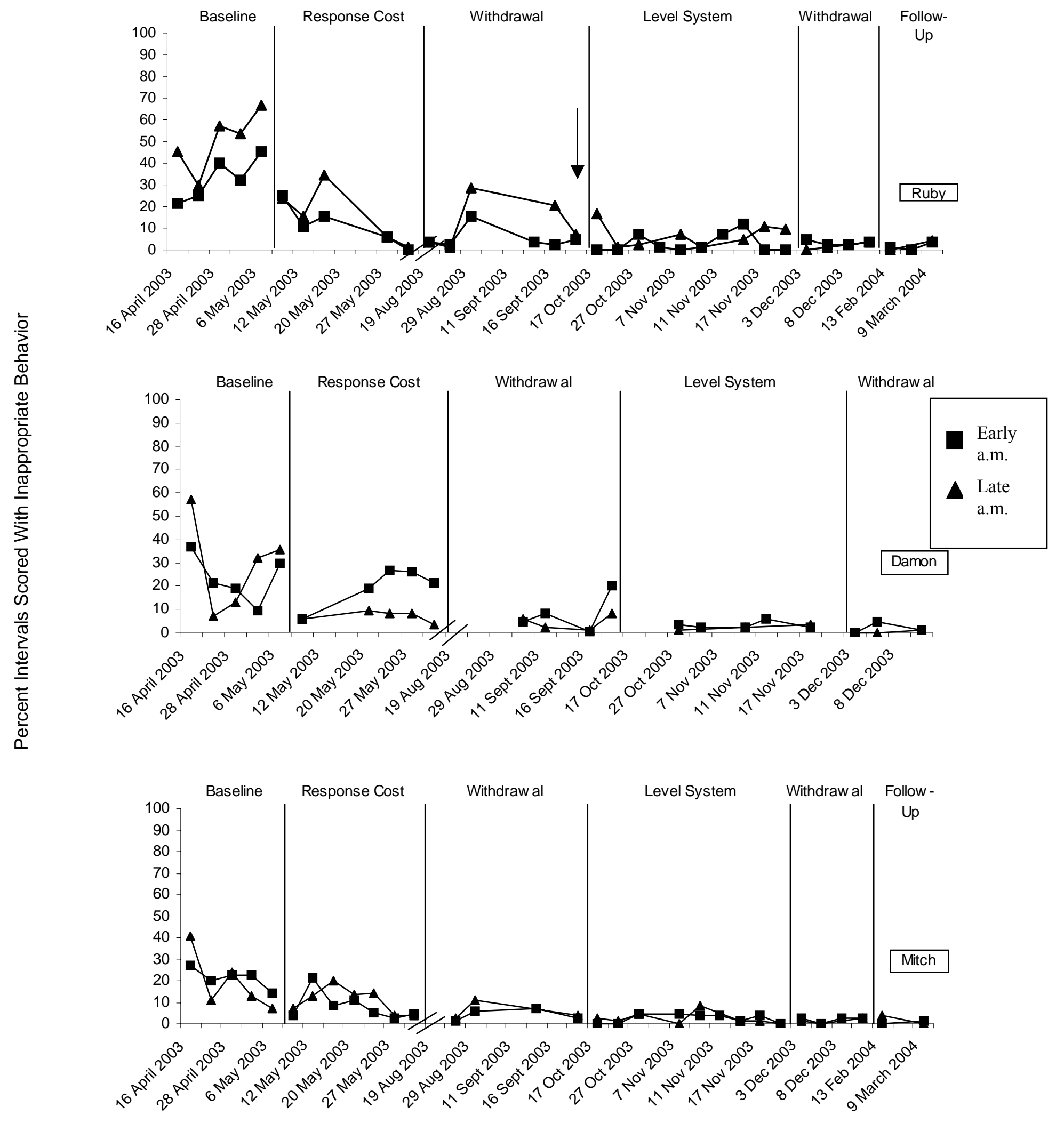

Date 


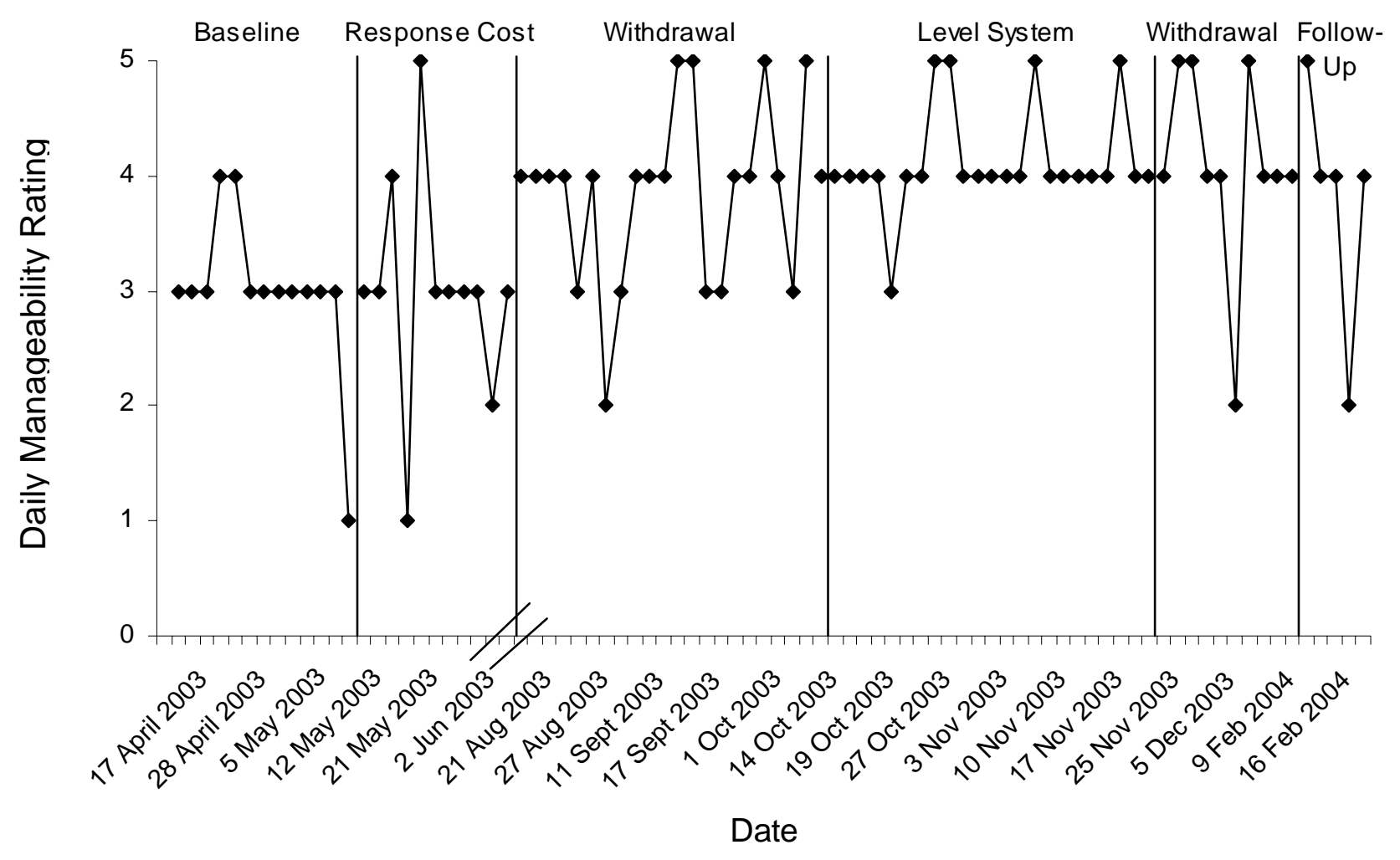




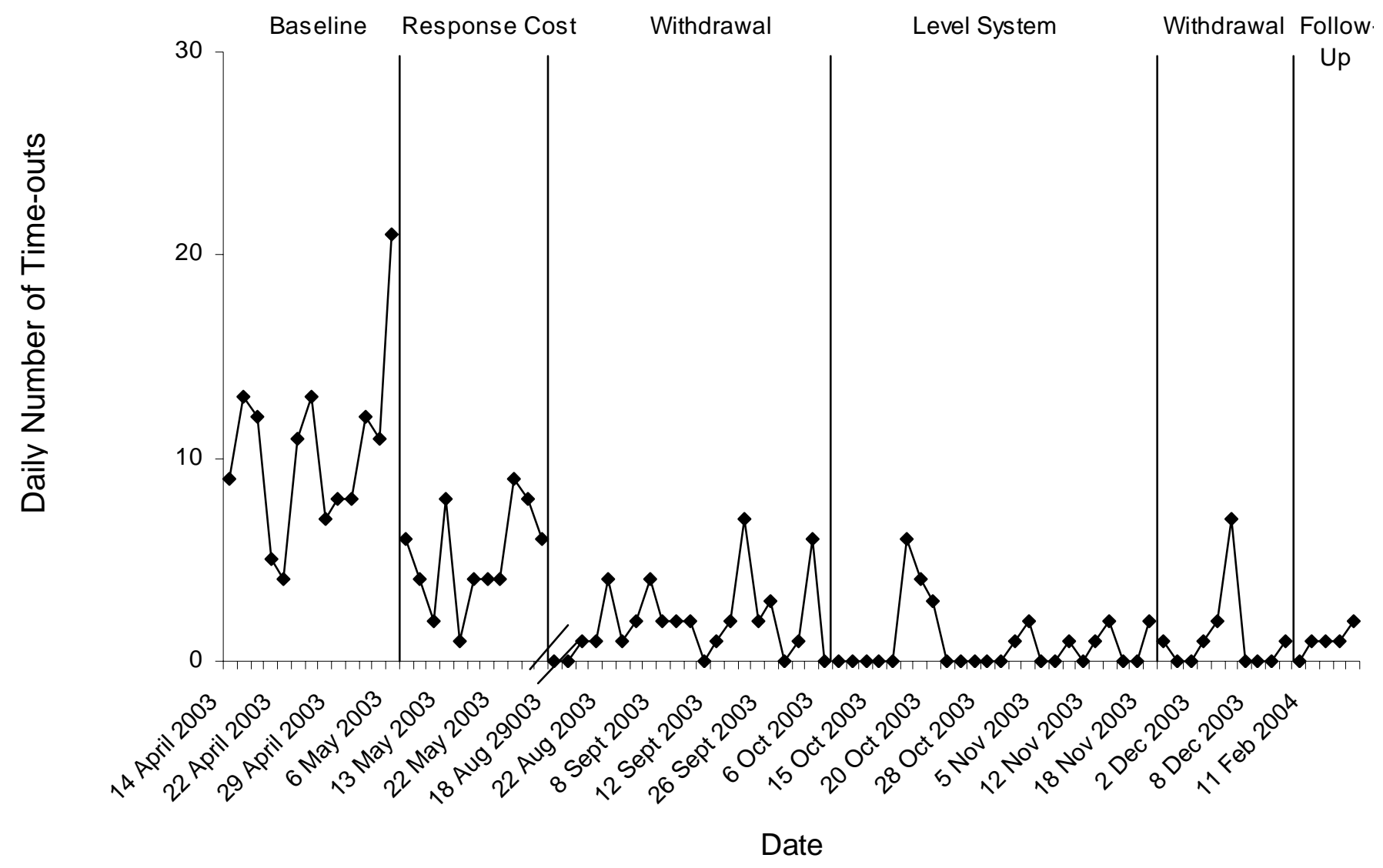



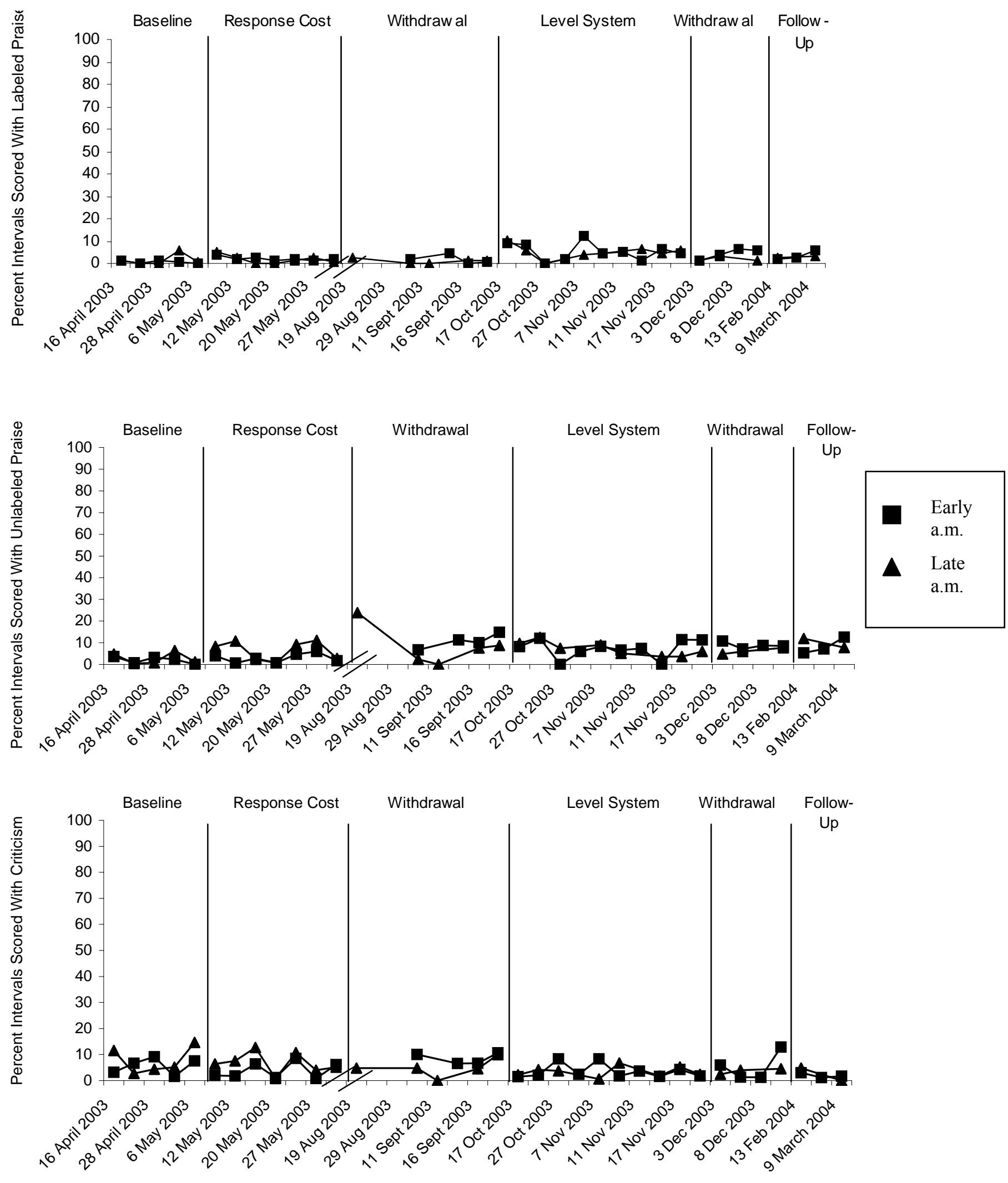

Date 